\title{
Altered generation of induced regulatory $T$ cells in the FVB.mdr1a-/- mouse model of colitis
}

\author{
SM Tanner ${ }^{1}$, EM Staley $^{1}$ and RG Lorenz $z^{1,2}$
}

The FVB.mdr1a ${ }^{-/-}$mouse, lacking the small molecule pump P-glycoprotein (P-gp), is a commonly used model for the study of spontaneous T cell-mediated colitis. In addition, MDR1 polymorphisms and P-gp deficiency in humans have been linked to the development of ulcerative colitis. We now demonstrate that mice with P-gp deficiency have decreased levels of Foxp3 ${ }^{+}$regulatory T cells (Tregs) in the intestinal lamina propria. This decrease is not due to either increased Treg apoptosis, altered Treg trafficking, or enhanced Treg plasticity to become Foxp ${ }^{+} \mathrm{IL}-17^{+}$cells. Instead, P-gp deficiency appears to restrict the development of induced Treg cells (iTregs), as fewer Foxp3 ${ }^{+}$iTregs developed from naive FVB.mdr1a ${ }^{-/-}$T cells both upon transforming growth factor- $\beta$ (TGF- $\beta$ ) treatment in vitro and after adoptive transfer into FVB.rag2 ${ }^{-/-}$recipients. Rather, in vitro TGF- $\beta$ treatment results in a IL- $17^{+} \mathrm{CD}^{+} \mathrm{T}$ cell. This failure of iTregs to develop explains the decrease in Foxp3 ${ }^{+}$Tregs in the FVB.mdr1a ${ }^{-/-}$intestine, representing a need to investigate this novel disease mechanism in human inflammatory bowel disease patients with MDR1 polymorphisms.

\section{INTRODUCTION}

Crohn's disease and ulcerative colitis are inflammatory bowel diseases (IBD) that demonstrate chronic inflammation throughout the digestive tract. A recognized animal model of IBD is the p-glycoprotein (P-gp)-deficient FVB mouse. These mice lack the multidrug resistance $(m d r 1 a)$ gene and have been described to spontaneously develop T cell-mediated colitis. ${ }^{1,2}$ $\mathrm{P}$-gp is an ATP-dependent, transmembrane small-molecule efflux pump (ABCB1), first described to confer resistance to several chemotherapeutic drugs, and recently linked to caspase3-dependent apoptosis. ${ }^{3-5}$ P-gp expression has been identified on both epithelial and immune cells, including $\mathrm{CD} 8{ }^{+}$cells and dendritic cells. ${ }^{6-10}$ Although P-gp deficiency has been linked to decreased epithelial barrier function, our lab has recently shown that P-gp deficiency also alters the response of immune cells in FVB.mdr1a $a^{-/-}$mice. ${ }^{11}$ Importantly, several polymorphisms of the human mdr1a homolog, MDR1, have been linked to ulcerative colitis, making this a relevant model with which to study the disease. ${ }^{12-14}$

The role of $\mathrm{CD}^{+}$regulatory $\mathrm{T}$ cells (Tregs) in the development of colitis has become a recent focal point of IBD research. Tregs can be of naturally occurring (nTregs) or induced (iTregs) origin, and are believed to suppress immune activity through several mechanisms, including the secretion of immunosuppressive molecules such as interleukin-10 (IL-10). ${ }^{15-17}$ Both nTregs and iTregs are most commonly identified by the expression of the transcription factor Foxp3 (forkhead box P3). ${ }^{18,19}$ Whereas nTregs arise naturally in the thymus, iTregs are generated in the periphery. Transforming growth factor- $\beta$ (TGF- $\beta$ ) has been shown as an important molecule in the induction of iTregs in both mice and humans, and these cells are generated in response to inflammation. ${ }^{15,20-23}$ Both subsets of Tregs, nTreg and iTreg, are believed to play an important role in gut homeostasis and limiting intestinal inflammation. ${ }^{24,25}$

Tregs have also been studied extensively in human IBD. It has been found that although Foxp3 ${ }^{+}$Tregs are decreased in peripheral blood, Tregs from the colonic mucosa of IBD patients appear to function normally to suppress $\mathrm{T}$ effector cell (Teff) proliferation in vitro using a conventional cell contact assay. ${ }^{26-28}$ In addition, treatment of patients with recombinant IL-10, a classic immunosuppressive cytokine produced by Tregs, has not yielded positive results. ${ }^{29,30}$ These observations suggest there could be another deficiency in Tregs unrelated to the number of cells, cell contact inhibition, or the secretion of IL-10 playing a role in human IBD.

In this study, we investigated the function of Tregs from FVB.mdrla $a^{-1-}$ before the development of histological intestinal inflammation. ${ }^{31}$ There are normal levels of Foxp $3^{+}$Tregs in the spleen and these Tregs are functional in cell contact suppression assays; however, there are fewer $\mathrm{CD} 4{ }^{+} \mathrm{Foxp} 3^{+}$cells in the

1Department of Pathology, University of Alabama at Birmingham, Birmingham, Alabama, USA. 2Department of Microbiology, University of Alabama at Birmingham, Birmingham, Alabama, USA. Correspondence: RG Lorenz (rlorenz@uab.edu) 
intestines of FVB. $m d r 1 a^{-/-}$mice. Interestingly, there were only minor changes in Treg apoptosis and the known gut-homing markers were not altered in a way that would explain the decrease in intestinal Tregs. FVB. $m d r 1 a^{-1-}$ mice also had no change in Foxp $3^{+} \mathrm{IL}_{-} 17^{+}$or Foxp $3^{+} \mathrm{IFN}-\gamma^{+}$cells in the intestinal lamina propria (LP). However, fewer Foxp $3^{+}$iTregs developed from naive FVB. $m d r 1 a^{-1-} \mathrm{T}$ cells both upon TGF- $\beta$ treatment in vitro and after adoptive transfer into FVB.rag $2^{-1-}$ recipients, suggesting that iTregs have altered induction in the absence of P-gp, resulting in an inability to suppress colonic inflammation.

\section{RESULTS}

FVB. dr1a $^{-/-}$mice have fewer intestinal Tregs, and FVB.mdr1a-l- Tregs display reduced suppression in vitro

In order to investigate the role of Tregs in the development of colitis in the FVB.mdr1 $1 a^{-1-}$ mouse, we first evaluated the number and percentages of $\mathrm{CD} 4{ }^{+} \mathrm{Foxp}^{+}{ }^{+}$Tregs in the FVB control and FVB. $m d r 1 a^{-1-}$ mice. Cells were isolated from the spleen, thymus, mesenteric lymph nodes (MLNs), Peyer's patches (PPs), small intestinal LP, and colonic LP of 6-8-weekold mice (before the development of intestinal inflammation) and subsequently stained for CD4 and Foxp3. Total lymphocyte numbers were found to be similar between the two groups in all tissues; however, an increase was observed in the percentage of $\mathrm{CD}^{+}$cells in the spleen, PP, and colonic LP (Figure 1a,b). Increased levels of $\mathrm{CD} 4^{+}$cells in FVB. $m d r 1 a^{-1-}$ mice could indicate early stages of inflammation. Treg percentages in the spleen, thymus, MLNs, and colonic LP were similar between FVB and FVB. $m d r 1 a^{-1-}$. Interestingly, FVB. $m d r 1 a^{-1-}$ mice had significantly fewer $\mathrm{CD} 4{ }^{+} \mathrm{Foxp} 3^{+}$cells in the PPs and small intestinal LP (Figure 1b). CD $4^{+}$Foxp $3^{+}$cell numbers mirrored the percentage observations (Figure 1c). Although inflammation is seen primarily in the colon in this model, several recent studies have shown that regulatory cell induction in the small intestine is necessary to protect from colitis, leading us to further investigate this decrease in Tregs in the PPs and small intestine. ${ }^{32,33}$

Although P-gp has been shown on $\mathrm{CD} 8{ }^{+}$cells, its expression on $\mathrm{CD} 4{ }^{+}$Tregs is unknown. To test for the presence P-gp expression on Tregs, a real-time PCR assay for the P-gp gene (Abcb1a) was performed. Magnetic-activated cell sorting (MACS) isolated $\mathrm{CD} 4{ }^{+} \mathrm{CD} 25^{+}$splenocytes expressed significantly higher levels of Abcbla RNA compared with $\mathrm{CD} 4^{+} \mathrm{CD} 25^{-}$cells (Figure 1d). Isolated splenic $\mathrm{CD} 4{ }^{+} \mathrm{CD} 25^{+}$cells showed $\sim 80 \%$ Foxp $3^{+}$ expression, indicating that a majority of the $\mathrm{CD} 4{ }^{+} \mathrm{CD} 25^{+}$cells used for this analysis were indeed Foxp $3^{+}$Tregs (Supplementary Figure $\mathbf{S 1}$ online). To test the function of P-gp on splenic $\mathrm{CD} 4{ }^{+} \mathrm{CD} 25^{+}$cells, the efflux of Rhodamine-123 (R-123), a fluorescent P-gp-specific substrate, was evaluated, utilizing $\mathrm{CD}^{+}$cells as a positive control (Supplementary Figure S2b online). ${ }^{7,34}$ As seen in Figure 1e, very little flux was observed from the splenic $\mathrm{CD} 4{ }^{+} \mathrm{CD} 25^{-}$Teffs, whereas one-third of the splenic $\mathrm{CD} 4{ }^{+} \mathrm{CD} 25^{+}$Tregs were capable of fluxing the dye out completely, indicating P-gp activity on this subset of cells. A time course of P-gp functional activity indicated that even after $4 \mathrm{~h}$ for $\mathrm{R}-123$ efflux, only a minority of the $\mathrm{CD} 4{ }^{+} \mathrm{CD} 25^{-}$cells were able to flux out the R-123 dye (Supplementary Figure S2a online). In addition, cells isolated from FVB.mdr1 $a^{-1-}$ mice were unable to significantly efflux R-123 (Figure 1e).

Because P-gp appears to only be functional on a subset of Tregs, we then evaluated whether the absence of P-gp altered the function of FVB.mdr1 $1 a^{-1-}$ Tregs. To accomplish this, an in vitro cell suppression assay was performed in which splenic FVB and FVB. $m d r 1 a^{-1-}$ Teffs and Tregs were isolated via MACS and cultured for $96 \mathrm{~h}$ in the presence of plate-bound antiCD3 and soluble anti-CD28. FVB Teffs were cultured with or without FVB or FVB.mdrla $a^{-1-}$ Tregs to compare suppression. Proliferation was measured by ${ }^{3} \mathrm{H}$-thymidine incorporation. FVB. $m d r 1 a^{-1-}$ Tregs were somewhat less capable of suppressing Teff proliferation to the same extent as the FVB Tregs in a 1:1 and 2:1 (Teff/Treg) ratio (Figure 2a). However, FVB. $m d r 1 a^{-1-}$ Tregs were able to successfully suppress the proliferation of wild-type FVB Teffs, and FVB Tregs could also suppress FVB. $m d r 1 a^{-1-}$ Teffs (Supplementary Figure S3 online).

Although the function of the Tregs in a cell contact-dependent system was important to test, we also wanted to determine what cytokines might be present in this culture system. To test this, cell supernatants were removed from the cells after $72 \mathrm{~h}$ of culture and analyzed by a multiplex system for interferon- $\gamma$ (IFN- $\gamma$ ), IL-10, IL-17A, and tumor necrosis factor- $\alpha$ (TNF- $\alpha$ ) (Figure 2b). Interestingly, no suppression of IFN- $\gamma$ or IL-17A was observed in the presence of either FVB or FVB.mdr1 $1 a^{-1-}$ Tregs. In addition, wild-type FVB Tregs seemed to suppress the secretion of TNF- $\alpha$ to a greater extent than FVB.mdr1 $a^{-1-}$ Tregs, whereas production of IL-10 was similar.

\section{Increased apoptosis and altered trafficking of Foxp $3^{+}$cells does not appear to be responsible for the decrease in Tregs in FVB. dr1a $^{-/-}$intestines}

Although our data indicated that the FVB.mdr1 $a^{-1-}$ Tregs that are present can suppress Teff proliferation in vitro, this information did not explain the reduced number and percentages of Tregs that was observed in the FVB. $m d r 1 a^{-1-}$ PPs and small intestinal LP. It has been shown in human tumors and leukemia cell lines that P-gp can be protective of caspase-induced apoptosis. ${ }^{4,5}$ Therefore, it is possible that Tregs deficient in P-gp may be more susceptible to apoptosis, resulting in fewer Foxp $3^{+}$ cells. To examine this potential mechanism, sections of intestine were fixed in cold Bouin's fixative and stained with fluorescently labeled antibodies for Foxp3 and cleaved caspase-3. Upon observation under the microscope, there were no Foxp $3^{+}$ cells that were also cleaved caspase $-3^{+}$in either the FVB or FVB. $m d r 1 a^{-1-}$ colonic samples (Figure $3 \mathbf{b}$ ). As a positive apoptosis control, we also analyzed sections of PPs. Multiple cells were positive for cleaved caspase-3; however, none of these were found to be also expressing Foxp3 in either strain (Figure 3a). Because of this very low level of apoptosis seen in vivo, we also wanted to check the sensitivity of Foxp $3^{+}$cells to the induction of apoptosis. To test this, cells were isolated, stimulated with anti-Fas ligand (CD95) overnight, and subsequently stained for CD4, Foxp3, and cleaved caspase-3. Cells were then analyzed via flow cytometry (Figure 3c). Significant changes were 

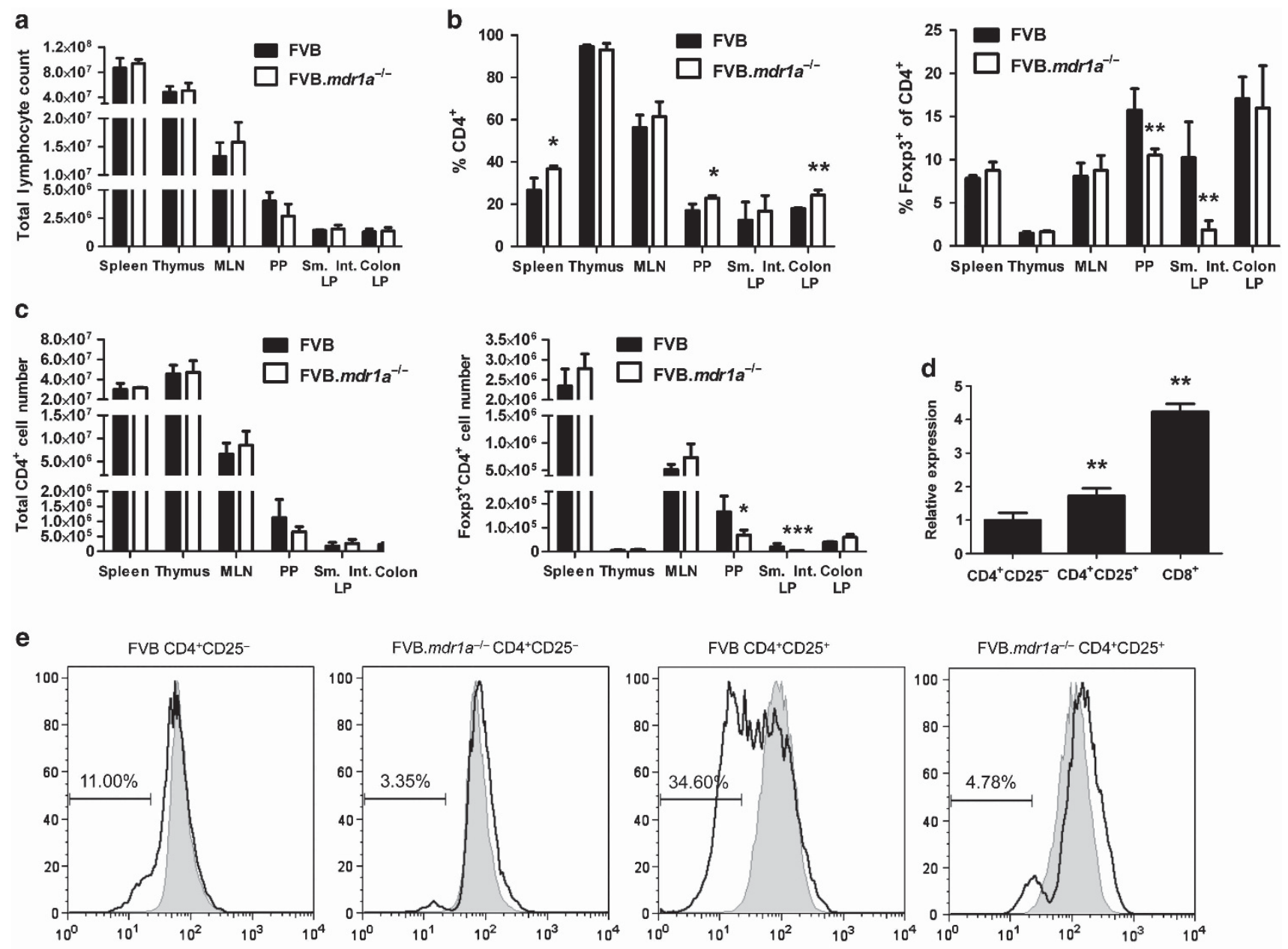

Rhodamine-123

Figure $1 \mathrm{CD}^{+}{ }^{+} \mathrm{CD} 25^{+}$cells express P-glycoprotein (P-gp) and FVB.mdr1a ${ }^{-/-}$mice display a smaller percentage of $\mathrm{CD}^{+}{ }^{+}$Foxp3 ${ }^{+}$regulatory $\mathrm{T}$ cells (Tregs) in intestinal lymphoid tissues. (a) Total cell lymphocyte counts after cell isolation. (b) Total percentage of CD4 ${ }^{+}$and Foxp3 ${ }^{+} \mathrm{CD} 4^{+}$cells from FVB and FVB. $m d r 1 a^{-1-}$ spleen, mesenteric lymph nodes (MLNs), Peyer's patches (PPs), and small intestinal (Sm. Int.) or colonic lamina propria (LP). Cells were collected from tissues and rested overnight before staining and flow cytometry. (c) Total cell numbers of $\mathrm{CD} 4^{+}$or $\mathrm{CD} 4^{+}$Foxp $3^{+}$cells within each population. (d) RNA expression of Abcb1a (P-gp) in splenic CD4 ${ }^{+} \mathrm{CD} 25^{-}$(set as a relative value of 1.0$), \mathrm{CD}^{+} \mathrm{CD} 25^{+}$, and $\mathrm{CD} 8^{+}(\mathrm{known}$ to express P-gp) splenocytes. (e) P-gp functional expression on CD4 ${ }^{+} \mathrm{CD} 25^{-}$and $\mathrm{CD} 4{ }^{+} \mathrm{CD} 25^{+}$cells. Magnetic-activated cell sorting (MACS) isolated cells were loaded with the P-gp-specific substrate rhodamine-123 (R-123) for $1 \mathrm{~h}$, followed by a $1 \mathrm{~h}$ flux of R-123. Shaded region represents loading control, whereas solid line indicates fluxed sample. Percentages indicate percent of cells fluxing R-123 through P-gp activity. Small amount of flux is a result of free diffusion of R-123 across cell membrane. Data are representative of (d) 2 or $(\mathbf{a}, \mathbf{b}, \mathbf{c}) 3$ separate experiments, with 3-4 male mice, $6-8$ weeks of age in each group per experiment. ${ }^{\star} P \leqslant 0.05 ;{ }^{* \star} P \leqslant 0.01 ;{ }^{* \star \star} P \leqslant 0.001$. Mean + s.d. is shown.

observed in the spleen, MLNs, and PPs, with anti-Fas ligand (CD95) inducing fewer cleaved caspase- $3^{+}$apoptotic Foxp3 ${ }^{+}$ cells in the FVB.mdr1 $1 a^{-1-}$ spleen and PPs. This observation would seem to suggest that the FVB.mdr1a $a^{-1-}$ mice do not have decreased Foxp $3^{+}$cells because of altered sensitivity to apoptosis. However, there was a slight, but significant, increase in Foxp $3^{+}$cleaved caspase- $3^{+}$cells in the FVB. $m d r 1 a^{-1-}$ MLNs. The importance of this observation is unclear, as it is unknown if MLNs are required for the presence of Tregs in the small intestinal or colonic LP. No difference in anti-CD95-induced apoptosis was observed between FVB and FVB. $m d r 1 a^{-1-}$ Foxp3 ${ }^{+}$cells from the intestinal LP, supporting the conclusion that increased apoptosis in intestinal tissue is not the cause for the decreased Treg numbers.
Another possible mechanism to explain fewer Tregs in the FVB. $m d r 1 a^{-1-}$ intestine is altered trafficking of Tregs to the intestinal tissues of FVB.mdr1 $a^{-1-}$ mice. To test this, we stained cells from the spleen, MLNs, PPs, and intestinal LP for Foxp3 and the intestinal trafficking markers $\alpha_{4} \beta_{7}, \operatorname{CD} 103$ ( $\alpha_{\mathrm{E}}$ integrin), CCR6, and CCR9 (Figure 4a,b). The trafficking marker with the most obvious changes in expression was CCR6, which demonstrated significantly increased expression on $\mathrm{CD} 4{ }^{+} \mathrm{Foxp} 3^{+}$cells in FVB. $m d r 1 a^{-1-}$ MLNs, PPs, small intestinal LP, and colonic LP. However, these data should be evaluated in light of the fact that CCR6 was also increased in $\mathrm{CD} 4^{+}$Foxp3 ${ }^{-}$cells from FVB. $m d r 1 a^{-1-}$ in these same tissues (Supplementary Figure S4 online). Although no striking differences were observed in CCR9 and CD103 on $\mathrm{CD}^{+}{ }^{+}$Foxp $3^{+}$cells in the colonic LP, 

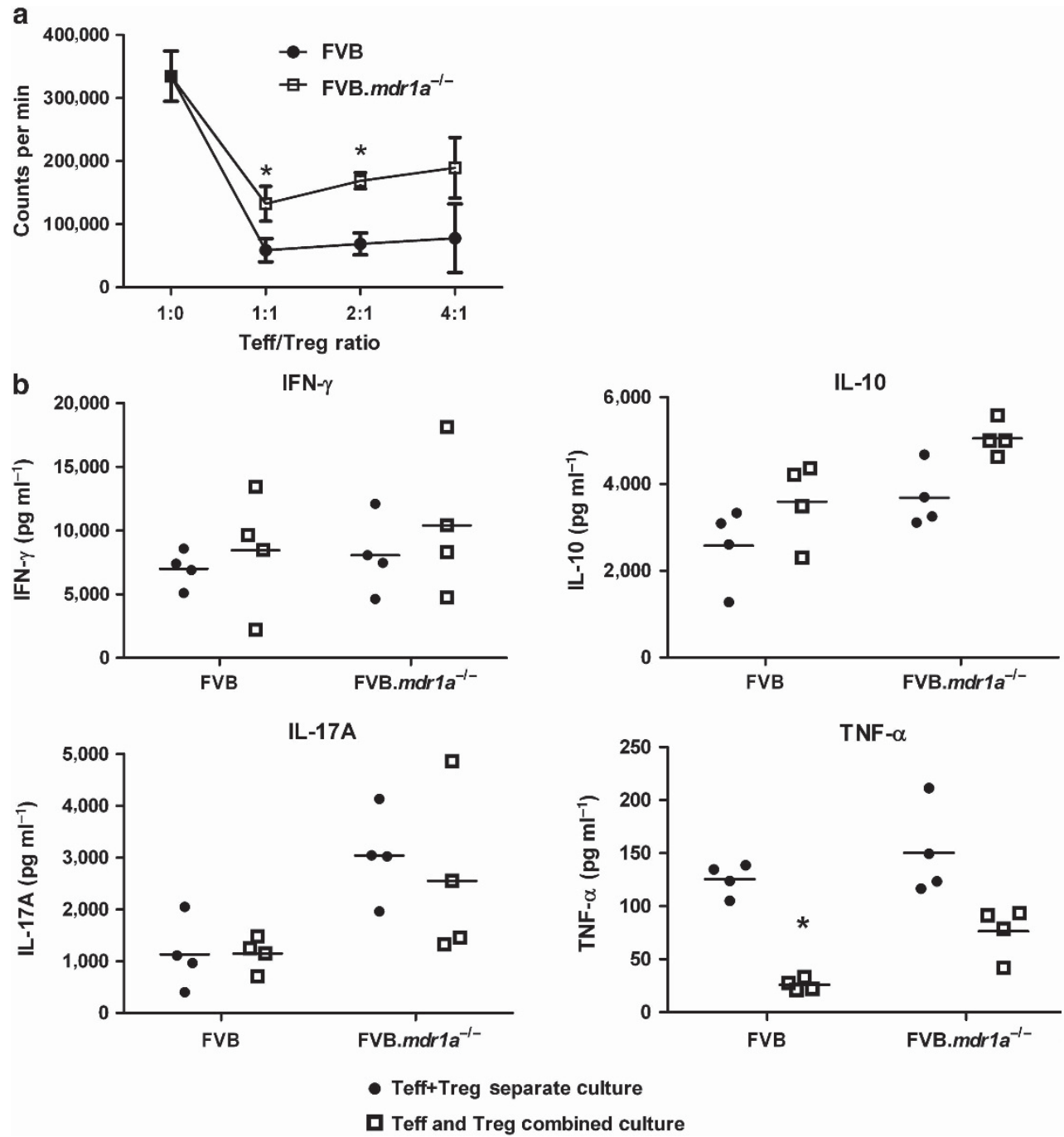

Figure 2 FVB. $m d r 1 a^{-/-} \mathrm{CD} 4{ }^{+} \mathrm{CD} 25^{+}$regulatory T cells (Tregs) suppress CD4 ${ }^{+} \mathrm{CD} 25^{-}$T effector cell (Teff) proliferation in vitro, but fail to suppress tumor necrosis factor- $\alpha$ (TNF- $\alpha$ ) secretion. (a) Magnetic-activated cell sorting (MACS) isolated FVB CD4 ${ }^{+}$CD25 $5^{-}\left(\right.$Teffs) and CD4 ${ }^{+}$CD25 $5^{+}$(Tregs) cells from either FVB or FVB.mdr1a ${ }^{-/-}$were cultured either separately or together for $96 \mathrm{~h}$ in the presence of anti-CD3 and anti-CD28. ${ }^{3} \mathrm{H}-\mathrm{Thymidine}$ was added for the final $24 \mathrm{~h}$ of culture. Assay was done at 1:1, 2:1, and 4:1 Teff/Treg ratio as indicated. (b) Supernatants from a were collected after $72 \mathrm{~h}$ and before the addition of ${ }^{3} \mathrm{H}$-Thymidine. Cytokine concentrations were determined using multiplex kits. Data are representative of three separate experiments, with 3-4 male mice, $6-8$ weeks of age in each group per experiment. IFN- $\gamma$, interferon- $\gamma$; IL, interleukin. ${ }^{*} P \leqslant 0.05$. (a) Mean + s.d. or (b) s.e.m. are shown.

FVB. $m d r 1 a^{-1-} \mathrm{CD} 4^{+} \mathrm{Foxp}^{+}{ }^{+}$cells did display a small, but numerically significant, increase in $\alpha_{4} \beta_{7}$ and CD103 in small intestinal LP. Based on the magnitude of this change, it not clear that it would have a significant functional effect, especially when it is considered that the mean fluorescence intensity of these trafficking markers was similar between the two strains (Supplementary Figure S5 online). In addition, FVB. $m d r 1 a^{-1-}$ Tregs showed a slight, but significant, decrease in $\alpha_{4} \beta_{7}$ in PPs and increase of CD103 in splenic Tregs. Total cell numbers for each marker did not show many significant changes (Figure $\mathbf{4 b}$ ). In addition, chemotaxis assays for CCL20 and CCL25, the chemokines for CCR6 and CCR9 respectively, did not show any difference in the functional ability of FVB. $m d r 1 a^{-1-} \mathrm{CD} 4{ }^{+} \mathrm{CD} 25^{+}$cells to traffic. Stromal cell-derived factor-1 $\alpha$ (SDF-1 $\alpha$ ) was utilized as a positive control to assure trafficking was occurring (Supplementary Figure S6 online).
Taken together, these data do not explain the significant decrease in $\mathrm{CD}^{+}{ }^{+} \mathrm{Foxp}^{+}$Tregs observed in the FVB. $m d r 1 a^{-1-}$ PPs and small intestine LP, although there is still a possibility that other trafficking phenomena could be playing a role in this model.

\section{P-gp deficiency does not increase Treg plasticity}

It has recently been shown in several disease models, including type 1 diabetes and IBD, that Treg cells can convert to other T helper (Th) phenotypes, especially to Th17-like cells. ${ }^{35-37}$ This led us to another possible explanation for a reduction of Tregs in FVB. $m d r 1 a^{-/-}$intestines: Foxp ${ }^{+}$cells are converting to secretion of proinflammatory cytokines, making them more like a Th1 or Th17 cell. To test for this, cells were isolated from the spleen, MLNs, PPs, and intestinal LP (Figure 5). Cells were then stimulated with phorbol 12-myristate 13-acetate 

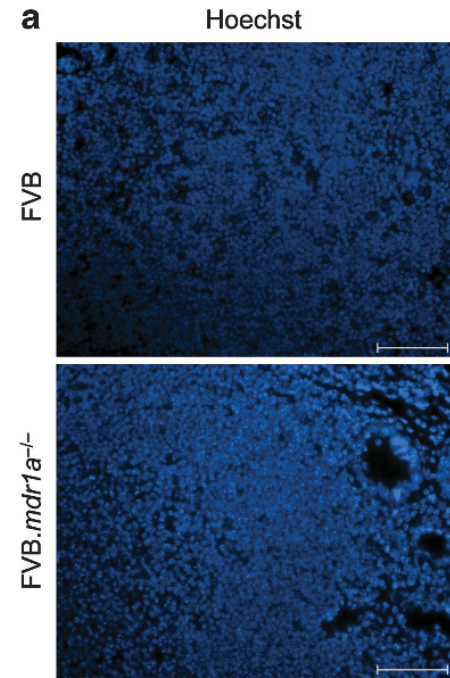

b

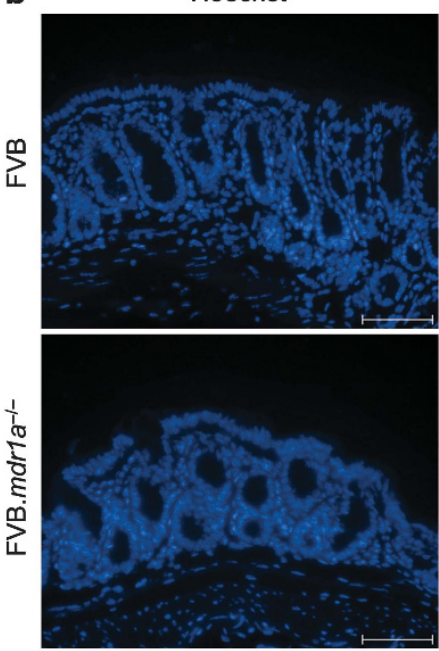

Hoechst

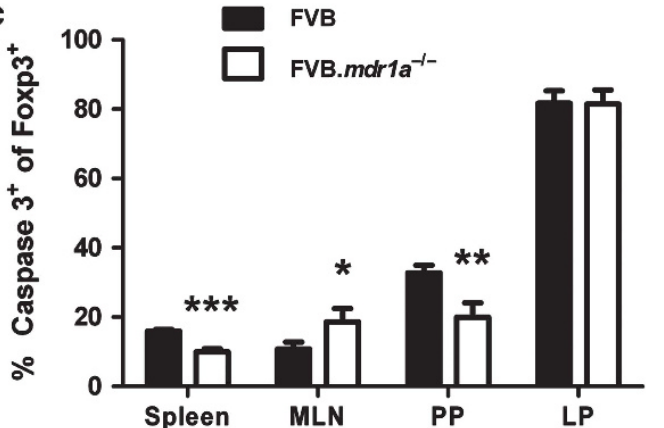

Foxp3-FITC
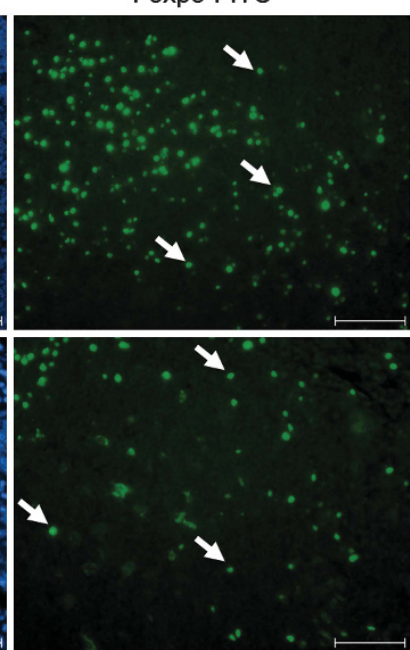

Foxp3-FITC
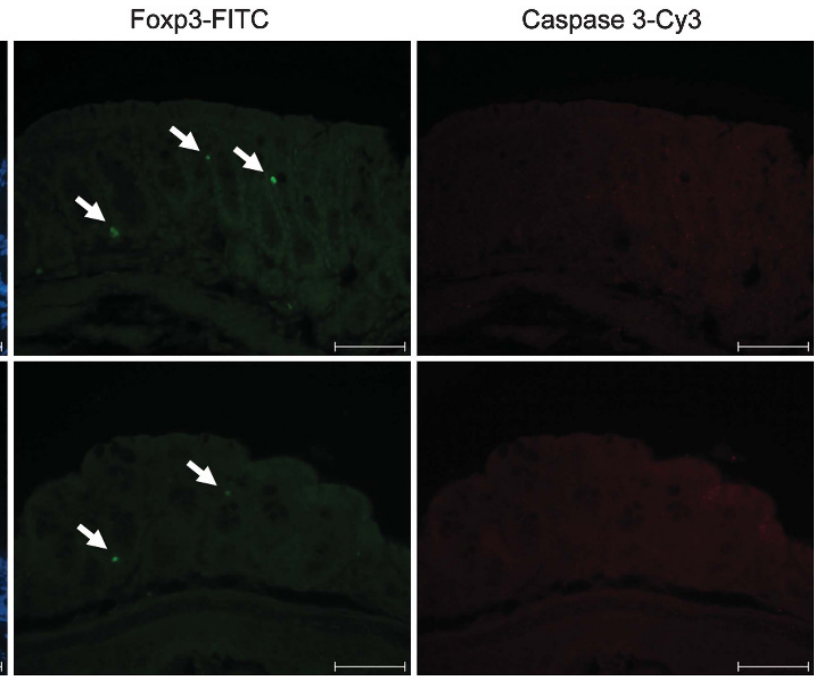

Merge

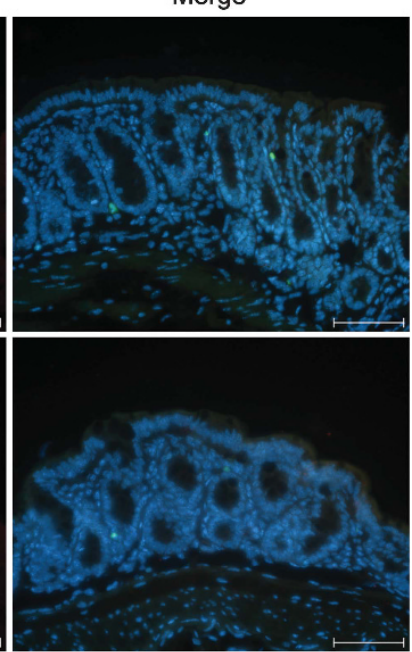

FVB

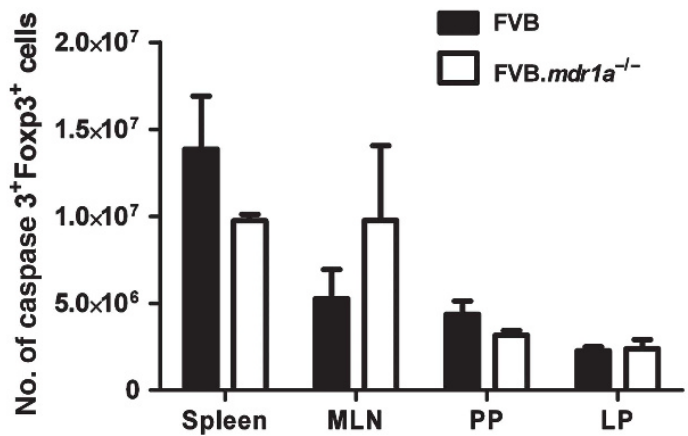

Figure 3 Intestinal FVB.mdr1a-/- Foxp3 ${ }^{+}$cells do not have increased levels of apoptosis. (a) Sections of Peyer's patches (PPs) and (b) distal colon were stained for Foxp3 (forkhead box P3) and cleaved caspase 3. Positive cells for stains are indicated by arrows in their respective panels. Images were captured at $\times 40$ magnification, and scale bars $=20 \mu \mathrm{m}$. (c) Cells were isolated from the spleen, mesenteric lymph nodes (MLNs), PP, and intestinal lamina propria (LP) and stimulated for $18 \mathrm{~h}$ with $10 \mu \mathrm{g} \mathrm{ml}^{-1}$ anti-CD95 to induce apoptosis. Cells were then stained for CD4, Foxp3, and cleaved caspase 3. Lymphocytes were gated based on forward scatter/side scatter. Cells were pre-gated on CD4 ${ }^{+}$cells before analysis of Foxp3 and cleaved caspase 3 expression. Note that the high number of apoptotic cells in the LP may be a result of the extensive enzymatic digesting necessary to isolate these cells. Data are shown from one experiment, but are representative of two separate experiments, with 3-4 male mice, 6-8 weeks of age in each group per experiment. ${ }^{\star} P \leqslant 0.05 ;{ }^{* \star} P \leqslant 0.01 ;{ }^{* \star} P \leqslant 0.001$. Mean + s.d. is shown.

and ionomycin in the presence of GolgiStop and subsequently stained for CD4, Foxp3, IL-17, or IFN- $\gamma$. There was no increase in $\mathrm{CD} 4^{+}$Foxp $3^{+} \mathrm{IL}-17^{+}$or $\mathrm{CD} 4^{+}$Foxp $3^{+} \mathrm{IFN}-\gamma^{+}$cells between the FVB and FVB.mdr1a $1 a^{-1-}$ mice in any tissue, including the colonic LP. This would indicate that Foxp3 cells from FVB. $m d r 1 a^{-1-}$ mouse strain are not any more likely to secrete 
a

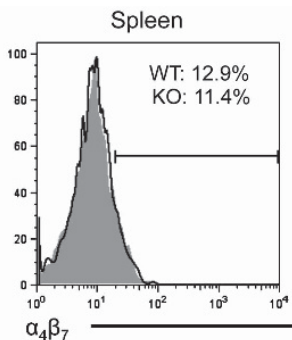

MLN

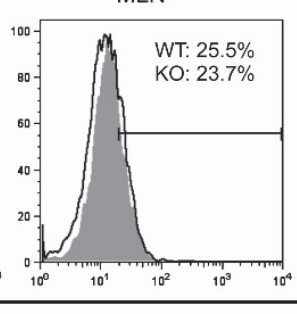

Peyer's patch

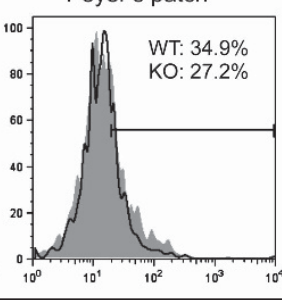

Sm. Int. LP

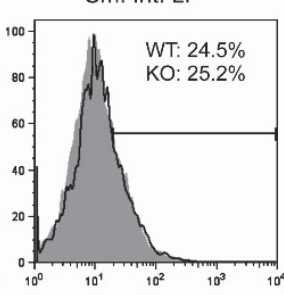

Colon LP
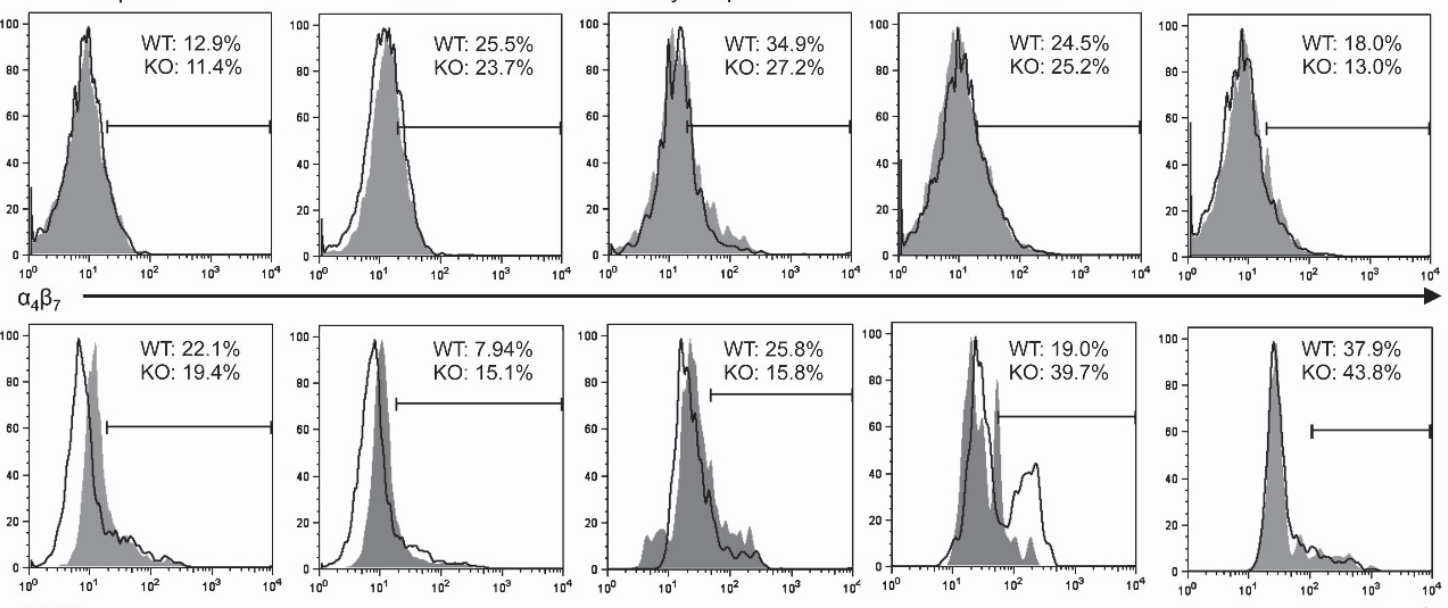

CCR6
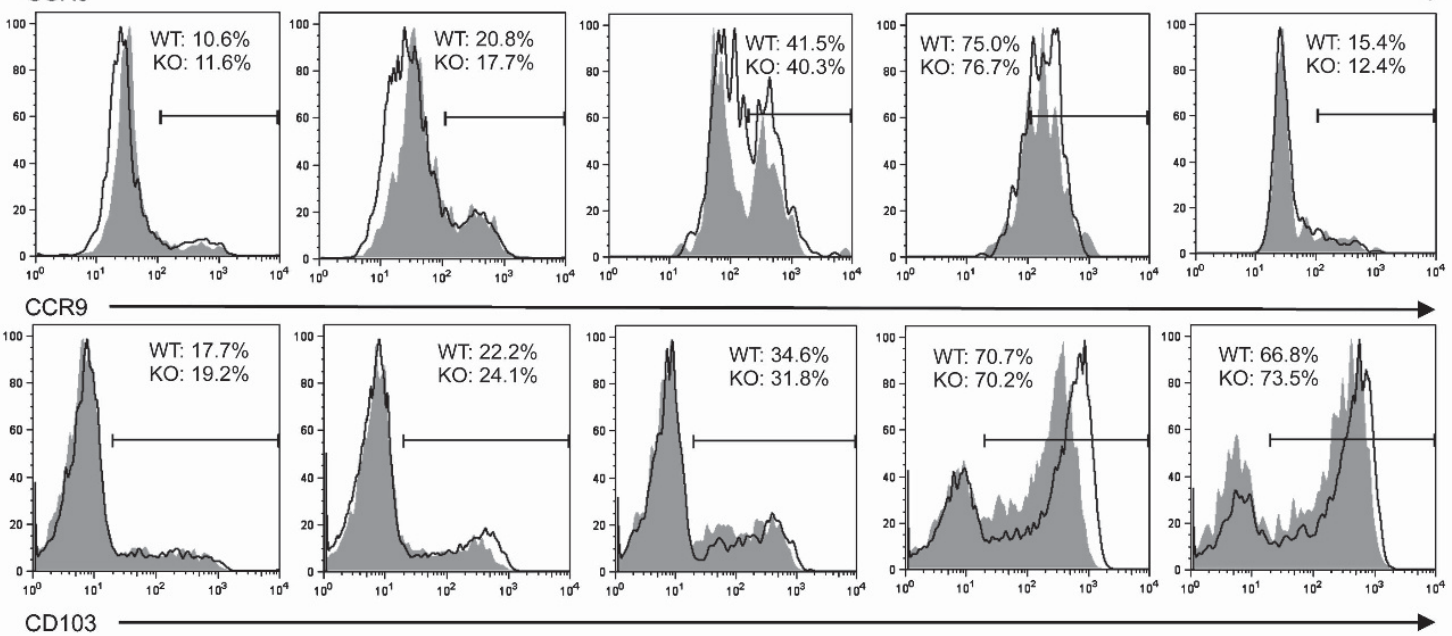

CD103
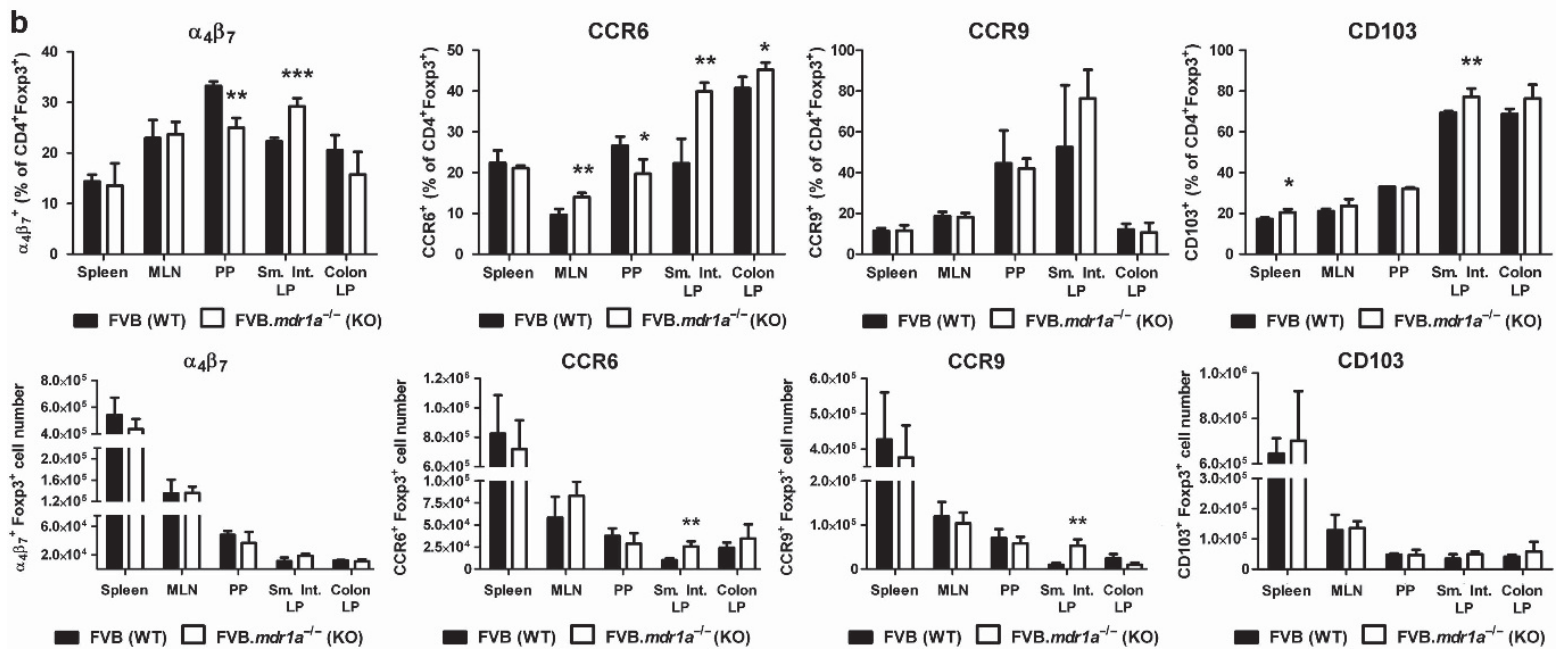

Figure 4 Altered trafficking of CD4+Foxp3+ regulatory T cells (Tregs) does not account for the decreased levels of Tregs in the FVB.mdr1a ${ }^{-/-}$ intestines. (a) Representative fluorescence-activated cell sorting (FACS) histogram plots for $\alpha_{4} \beta_{7}$, CCR6, CCR9, and CD103 expression on CD4 ${ }^{+}$Foxp3 ${ }^{+}$Tregs in the spleen, mesenteric lymph nodes (MLNs), Peyer's patches (PPs), small intestinal (Sm. Int.) lamina propria (LP), and colonic LP. Cells were isolated from tissues and rested overnight before staining. Lymphocytes were gated based on forward scatter/side scatter and then subsequently gated on $\mathrm{CD} 4^{+}{ }^{+} \mathrm{Fxp}^{+}$cells. Percentages shown are for only this representative FACS plot; shaded region represents FVB, whereas solid line indicates FVB.mdr1a $a^{-/-}$. KO, knockout; WT, wild type. (b) Histograms representing the mean percentages (upper panels) and cell counts (lower panels) from analysis of each individual histogram gated on $\mathrm{CD}^{+}{ }^{+} \mathrm{Foxp} 3^{+}$as represented in a. Data shown are the means from one representative experiment, which was repeated twice. Each experiment was individually analyzed, $3-4$ male mice, $6-8$ weeks of age. ${ }^{*} P \leqslant 0.05$; ${ }^{\star \star} P \leqslant 0.01 ;{ }^{* \star \star} P \leqslant 0.001$. Mean + s.d. is shown. 
a
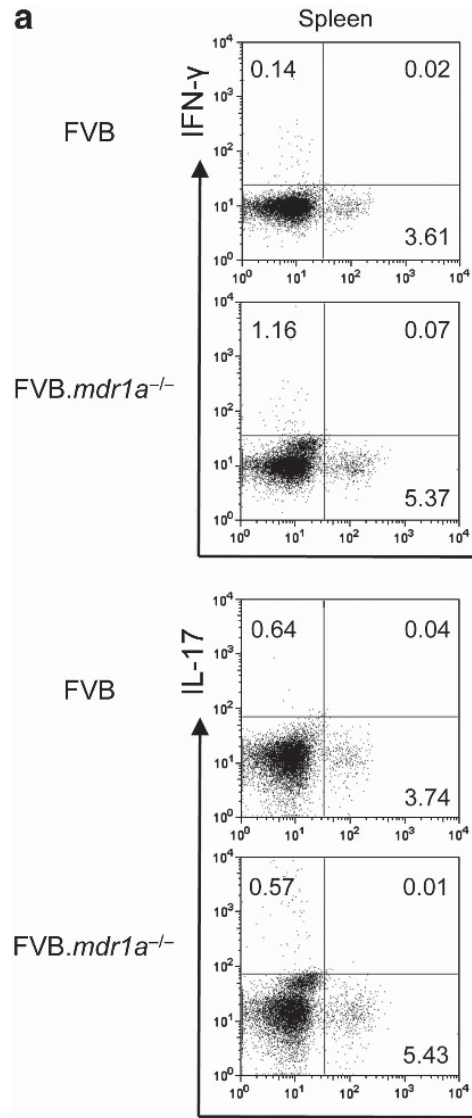
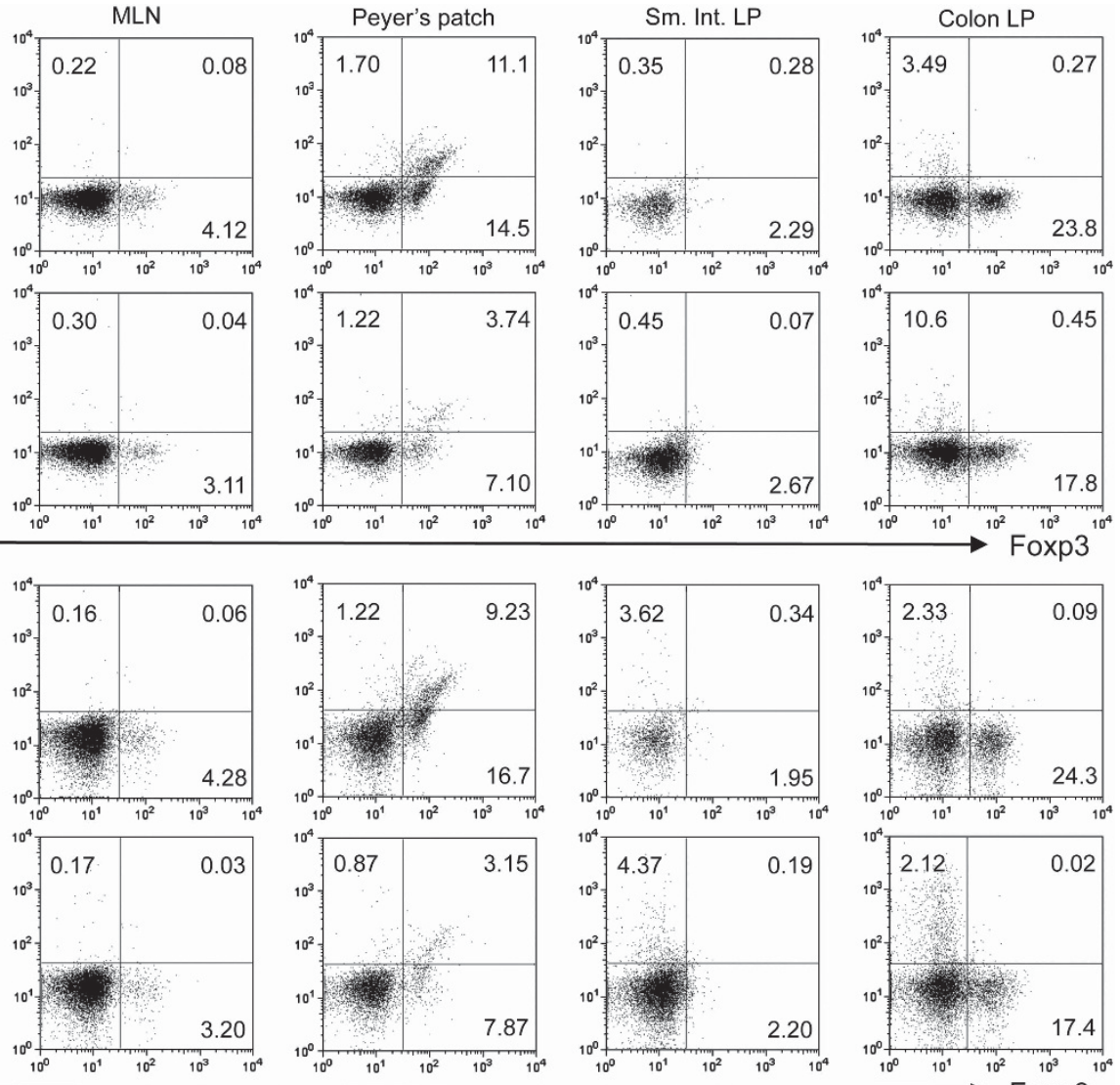
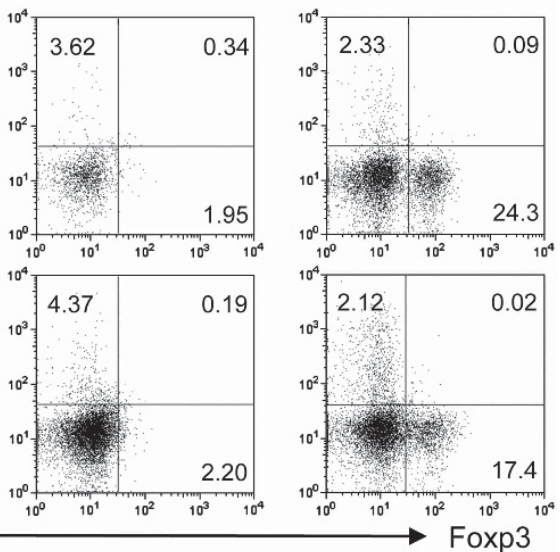

b

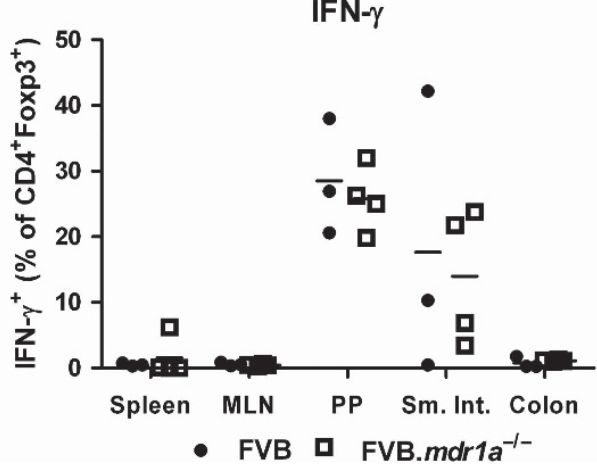

IL-17

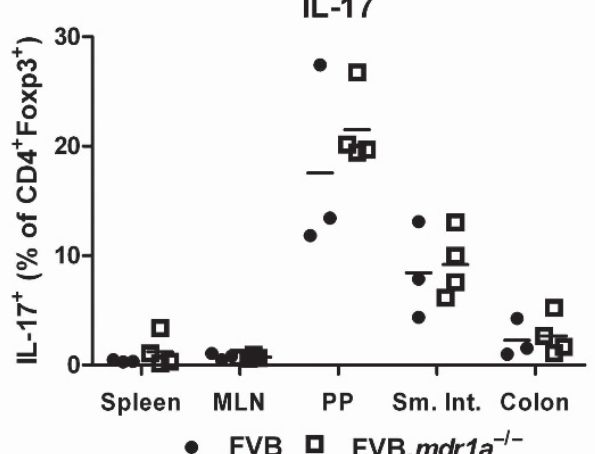

Figure 5 FVB.mdr1a ${ }^{-1-}$ CD4 ${ }^{+}$Foxp3 ${ }^{+}$cells do not have higher coexpression of interferon- $\gamma($ IFN- $\gamma$ ) or interleukin-17 (IL-17) in the intestines. (a) Representative fluorescence-activated cell sorting (FACS) plots of Foxp3 (forkhead box P3) vs. IFN- $\gamma$ or Foxp3 vs. IL-17A in the spleen, mesenteric lymph nodes (MLNs), Peyer's patches (PPs), small intestinal (Sm. Int.) lamina propria (LP), and colonic LP. Cells were isolated from tissues and rested overnight before stimulation with phorbol 12-myristate 13-acetate (PMA) and ionomycin in the presence of monensin. Cells were then stained for CD4, Foxp3, IFN- $\gamma$, and IL-17. Lymphocytes were gated based on forward scatter/side scatter and subsequently gated on CD4 ${ }^{+}$cells. (b) Dot plots representing the individual mice and the mean from one representative experiment. Data were reproduced in three separate experiments with three mice male mice (6-8 weeks of age) per group. Mean + s.d. is shown.

proinflammatory cytokines than the FVB control. Although the FVB. $m d r 1 a^{-1-}$ Foxp $^{+}$Tregs did not appear to produce more IFN- $\gamma$ or IL-17, FVB.mdr1 $1 a^{-1-}$ CD $4^{+}$Foxp3 ${ }^{-}$Teffs did produce higher levels of IL-17, particularly in the colon (Supplementary Figure $\mathbf{S 7}$ online). This is indicative of early inflammation being detected by immune assays in these mice, before it could be detected histologically. Our laboratory has also previously shown that FVB.mdr1 $a^{-1-}$ mice have increased INF- $\gamma$ and IL-17 mRNA levels in the intestine at a young age. ${ }^{31}$

\section{FVB.mdr1a ${ }^{-/-} \mathrm{CD}^{+}{ }^{+} \mathrm{CD}^{2} 5^{-}$naive T cells fail to become iTregs upon treatment with TGF- $\beta$}

Although P-gp-deficient Foxp $3^{+}$Tregs do not have an increased propensity to shift to the production of inflammatory cytokines, it is possible that these mice may have a defect in the induction of iTregs from naive $\mathrm{T}$ cells. iTregs can be induced in vitro by treatment with TGF- $\beta$; however, if IL- 6 is also present then Th17 are the predominant $\mathrm{T}$ cells produced. ${ }^{15,38}$ As there is an increased percentage of $\mathrm{CD}^{+}{ }^{+}$cells that produce IL-17 in the 
colon of FVB.mdr1a $a^{-/-}$mice, we next investigated the hypothesis that P-gp deficiency altered the iTreg/Th17 axis (Figure 6). $\mathrm{CD} 4{ }^{+} \mathrm{CD} 25^{-}$or $\mathrm{CD} 4{ }^{+} \mathrm{CD} 25^{+}$cells were cultured in the presence IL- 6 or TGF- $\beta$, as well as in combination. The cells were then analyzed for Foxp3 and IL-17 expression via flow cytometry, and the supernatants were analyzed for IL-10, IL-17A, and IFN $-\gamma$ via enzyme-linked immunosorbent assay. Interestingly, treatment with TGF- $\beta$, a cytokine known to induce Foxp3 expression and to be responsible for iTreg generation, resulted in significantly fewer Foxp $3^{+}$cells from the FVB. $m d r 1 a^{-1-} \mathrm{CD} 4{ }^{+} \mathrm{CD} 25^{-}$cultures $(21.74 \pm 0.12 \%)$ as the FVB CD $4^{+} \mathrm{CD} 25^{-}$cultures (38.91 $\left.\pm 1.83 \%\right)$. In addition, TGF$\beta$-treated FVB. $m d r 1 a^{-1-} \mathrm{CD} 4{ }^{+} \mathrm{CD} 25^{-}$cells produced significantly more IL- 17 -secreting cells $(6.75 \pm 0.24 \%$ vs. $1.14 \pm 0.08 \%)$ and Foxp $3^{+} \mathrm{IL}-17^{+}$double-positive cells $(5.45 \pm 0.45 \%$ vs. $0.80 \pm 0.28 \%)$ than FVB CD $4^{+} \mathrm{CD} 25^{-}$cells. IL- 6 had smaller effects, as IL-6-only treatment did produce more IL- $17^{+}$cells from the FVB.mdr1 $1 a^{-1-} \mathrm{CD} 4^{+} \mathrm{CD} 25^{-}$starting culture, although these cells did produce more IL- $17^{+}$cells with no treatment (Figure 6a). When Treg-like CD ${ }^{+} \mathrm{CD} 25^{+}$cells were used as the starting population, there was no significant difference in Foxp $3^{+}$cells between the FVB and FVB. $m d r 1 a^{-1-}$ untreated cultures, aside from a small decrease in FVB. $m d r 1 a^{-1-}$ Foxp3 ${ }^{+}$ cells when treated with both IL- 6 and TGF- $\beta$ (Figure 6a). These data would suggest that FVB. $m d r 1 a^{-1-} \mathrm{CD} 4^{+}$cells have a reduced ability to become iTregs in the presence of TGF- $\beta$. To attempt to estimate the number of iTregs and nTregs in vivo, we also looked at the expression of Helios. Although controversial, Helios has been described as a transcription factor that is thought to be expressed in nTreg, but not iTregs. ${ }^{39,40}$ Percentages of Foxp $3^{+} \mathrm{Helios}^{+}$cells were similar between FVB and FVB. $m d r 1 a^{-1-}$, showing that nTreg percentages were unchanged between FVB and FVB.mdr $1 a^{-1-}$ groups; however, increased numbers of Foxp $3^{+}$Helios $^{+}$cells were observed in the FVB. $m d r 1 a^{-1-}$ MLNs, PPs, and colonic LP (Supplementary Figure S8 online), suggesting increased proportions of nTregs vs. iTregs.

In addition to the cell expression data above, the cytokines secreted by these cells also support the fact that FVB.mdr1 $a^{-/-}$ $\mathrm{CD} 4^{+} \mathrm{CD} 25^{-}$Teffs seem to be more likely to produce proinflammatory cytokines than FVB cells. Although FVB. $m d r 1 a^{-1-}$ Teffs secrete more IL- 10 when treated with TGF- $\beta$, FVB. $m d r 1 a^{-1-}$ Teffs secrete much more IL-17A at baseline and under most treatments. In addition, FVB.mdr1 $1 a^{-1-}$ Teffs also secrete significantly more IFN- $\gamma$ under most conditions (Figure $6 \mathbf{b}$ ). There were few differences in cytokine secretion when $\mathrm{CD} 4{ }^{+} \mathrm{CD} 25^{+}$ Tregs were treated (Figure 6b). Lastly, it is important to note that freshly isolated splenic CD4 ${ }^{+} \mathrm{Foxp}^{-}$(and $\mathrm{CD} 4^{+} \mathrm{Foxp}^{+}$) cells from FVB and FVB. $m d r 1 a^{-1-}$ express similar levels of the activation markers CD44, CD62L, and CD69, indicating that the activation states of these cells is the same (data not shown). Taken together, these data suggest that naive FVB. $m d r 1 a^{-1-}$ $\mathrm{CD} 4{ }^{+} \mathrm{CD} 25^{-}$cells responded to TGF- $\beta$ by increasing IL- 10 and IL-17 production, instead of becoming true Foxp3-expressing iTregs. This mechanism is one explanation for the decrease in $\mathrm{CD} 4{ }^{+} \mathrm{Foxp}^{+}$cells in the intestines of FVB. $m d r 1 a^{-/-}$mice.

\section{FVB. $m d r 1 a^{-/-}$CD4 ${ }^{+} \mathrm{CD}^{-} 5^{-}$cells show impaired Foxp3 ${ }^{+}$ iTreg generation in vivo}

Although the decreased level of Foxp $3^{+}$iTreg generation in vitro was intriguing, it was also necessary to determine if this defect in iTreg generation occurred in vivo. An adoptive transfer was performed to test the ability of FVB. $m d r 1 a^{-/-}$naive $\mathrm{CD} 4{ }^{+} \mathrm{CD} 25^{-}$cells to become Foxp ${ }^{+}$iTregs in vivo. Splenic $\mathrm{CD} 4{ }^{+} \mathrm{CD} 25^{-}$cells from FVB and FVB. $m d r 1 a^{-/}$were sorted via fluorescence-activated cell sorting (FACS). Sorted CD $4^{+} \mathrm{CD} 25^{-}$ cells were found to be $\sim 0.3 \%$ Foxp $3^{+} .1 \times 10^{6} \mathrm{CD} 4^{+} \mathrm{CD} 25^{-}$cells from either FVB or FVB. $m d r 1 a^{-/-}$were injected intraperitoneally into FVB.Rag2 ${ }^{-1-}$ recipients. After 2 weeks, spleen, MLNs, and intestinal LP tissue was harvested and analyzed for Foxp3 expression, indicating the generation of iTregs. In concordance with the in vitro data, FVB. $m d r 1 a^{-/-} \mathrm{CD} 4{ }^{+} \mathrm{CD} 25^{-}$ cells appear to also have an impaired ability to generate iTregs in vivo. FVB.mdr $1 a^{-1-}$ had a significantly smaller percentage of Foxp $3^{+}$cells in the $\mathrm{CD}^{+}$population in both the spleen $(4.53 \%$ vs. $1.73 \%)$ and the MLNs (4.16\% vs. $1.39 \%)$, as well as decreased total Foxp $3^{+}$numbers in both tissues (Figure 7). No Foxp $3^{+}$ cells were detected in the intestinal (small intestine or colon) LP in the recipients of either strain.

\section{DISCUSSION}

Several MDR1 polymorphisms, which decrease P-gp efflux function, have been associated with human IBD. ${ }^{12-14}$ In addition, FVB mice deficient in P-gp also develop a spontaneous, T cell-mediated colitis. ${ }^{1,2}$ Although some studies have shown FVB. $m d r 1 a^{-1-}$ mice to have altered intestinal barrier function because of P-gp expression in intestinal epithelial cells, a recent study by our laboratory suggests that a hematopoietic component in these animals also plays an important role in disease development. ${ }^{11,41,42}$ Our current study supports the conclusion that in the absence of $\mathrm{P}$-gp, the $\mathrm{CD} 4{ }^{+} \mathrm{CD} 25^{+}$suppression of $\mathrm{CD}^{+}$cell proliferation in vitro is suboptimal, and the generation of Foxp $3^{+}$cells from $\mathrm{CD} 4{ }^{+} \mathrm{CD} 25^{-}$cells both in vitro and in vivo is dramatically inhibited. In order to determine if expression of P-gp on $\mathrm{CD} 4{ }^{+} \mathrm{CD} 25^{+}$Tregs could play a role in this defective generation of Foxp $3^{+}$cells, we first determined if Tregs expressed P-gp. Indeed, increased levels of $A b c b 1 a$ (P-gp) RNA were detected in $\mathrm{CD} 4{ }^{+} \mathrm{CD} 25^{+}$Tregs, and P-gp activity was detected in a higher percentage of $\mathrm{CD} 4{ }^{+} \mathrm{CD} 25^{+}$cells, than in $\mathrm{CD} 4{ }^{+} \mathrm{CD} 25^{-}$cells. More importantly, we also observed a decrease in $\mathrm{CD}^{+}{ }^{+} \mathrm{Foxp}_{3}{ }^{+}$Tregs in the PPs and small intestinal LP of FVB. $m d r 1 a^{-1-}$ mice $\sim 4$ weeks before histological intestinal inflammation typically occurs, implying that this could be a potential mechanism leading to the development of disease. However, we did not detect a decrease in $\mathrm{CD} 4{ }^{+} \mathrm{Foxp}^{+}{ }^{+}$Tregs in the colonic LP, although inflammation in the FVB.mdr1 $a^{-1-}$ model of colitis is typically limited to the colon. This is intriguing in light of recent studies, which suggest the requirement for induction of Tregs in the small intestine in order to prevent colitis in the dextran sulfate sodium and $\mathrm{CD} 4^{+}$transfer models of colitis. ${ }^{32,33}$ In addition, the development of Th17 cells has also been shown to be regulated in the small intestine, further implicating the small intestine as a vital site of Th cell development, 

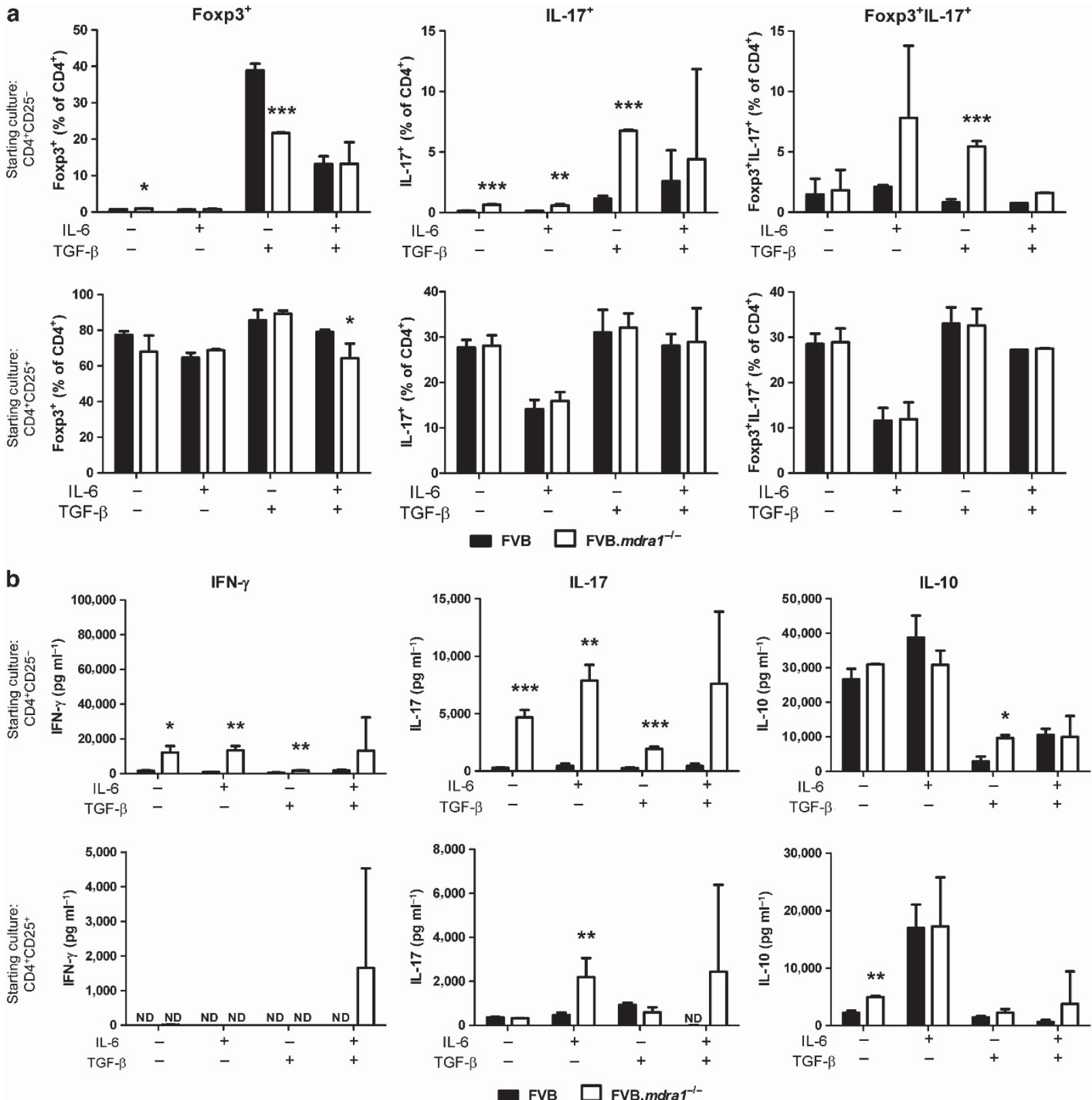

Figure 6 FVB. $m d r 1 a^{-/-}$CD4 ${ }^{+}$CD25- cells do not become Foxp3 ${ }^{+}$cells upon treatment with transforming growth factor- $\beta$ (TGF- $\beta$ ) and are more likely to become Foxp3- IL-17+ cells. (a) Magnetic-activated cell sorting (MACS) isolated CD4+ ${ }^{+} \mathrm{CD}^{+} 5^{-}$(upper panels) and CD4 ${ }^{+}$CD25 $5^{+}$(lower panels) cells were cultured for $72 \mathrm{~h}$ with CD3 and CD28 stimulation in the presence of $25 \mathrm{ng} \mathrm{ml}^{-1}$ interleukin- 6 (IL-6) alone, $5 \mathrm{ng} \mathrm{ml}^{-1} \mathrm{TGF}_{-} \beta$ alone, or IL-6 and TGF- $\beta$ together. Cells were rested for $24 \mathrm{~h}$ and then subsequently stained for CD4, Foxp3, and IL-17. (b) Supernatants from a were collected after $72 \mathrm{~h}$ of culture and analyzed for IL-10, IL-17, and interferon- $\gamma$ (IFN- $\gamma$ ) secretion by enzyme-linked immunosorbent assay (ELISA). It is important to note that freshly isolated splenic CD4 ${ }^{+}$Foxp3 ${ }^{-}$(and CD4 ${ }^{+}$Foxp3 $^{+}$) cells from FVB and FVB.mdr1a ${ }^{-/}$express similar levels of the activation markers CD44, $\mathrm{CD} 62 \mathrm{~L}$, and CD69, indicating that the activation states of these cells is the same (data not shown). Results are representative of two independent experiments, with 3-4 male mice, $6-8$ weeks of age in each group per experiment. ND, not detected (below detectable level of assay). ${ }^{*} P \leqslant 0.05$; ${ }^{* *}, P \leqslant 0.01 ;{ }^{* * *}, P \leqslant 0.001$. Mean of 3-4 mice (analyzed separately) + s.d. is shown.

particularly in the FVB.mdr1a-/-, where IL-17 plays a prominent role in colonic inflammation. ${ }^{43}$

Although there appear to be fewer Tregs present in the FVB. $m d r 1 a^{-1-}$ small intestine, these Tregs can suppress Teff proliferation in vitro, although not quite as effectively as wildtype Tregs. In addition, the FVB Tregs can suppress TNF- $\alpha$ secretion to a significant level, whereas the FVB.mdr $1 a^{-/-}$Tregs cannot. These two findings indicate that even the Tregs that do get to the colon may not function effectively. Our findings are particularly interesting as it is now clear that in many patients, anti-TNF- $\alpha$ therapies are very effective in the treatment of IBD. These anti-TNF- $\alpha$ antibodies might be filling a potential void left by defective Tregs in human IBD patients. It has even been reported that anti-TNF- $\alpha$ therapy increases the number and 

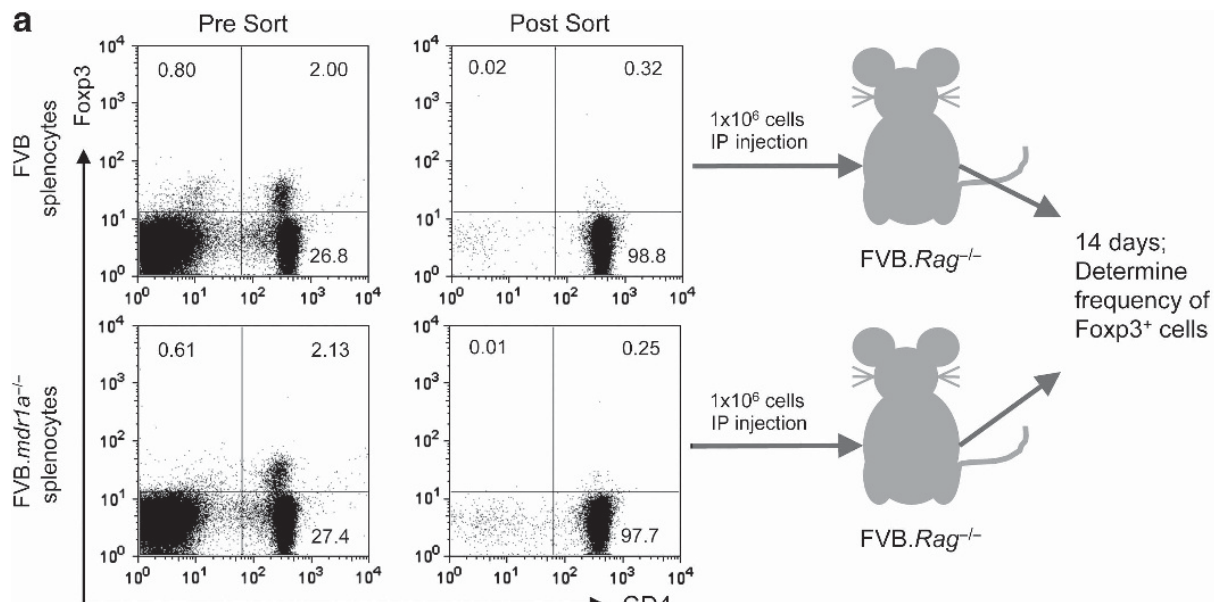

b
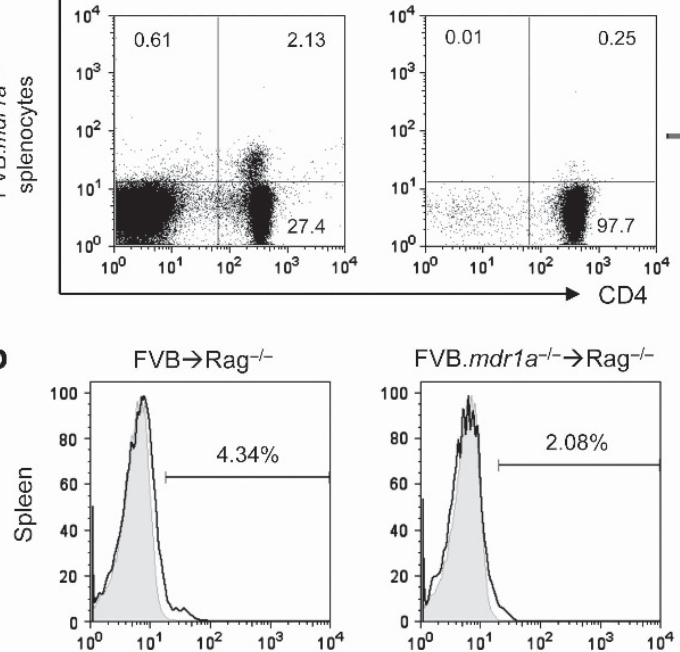

Foxp $3^{+}$cells
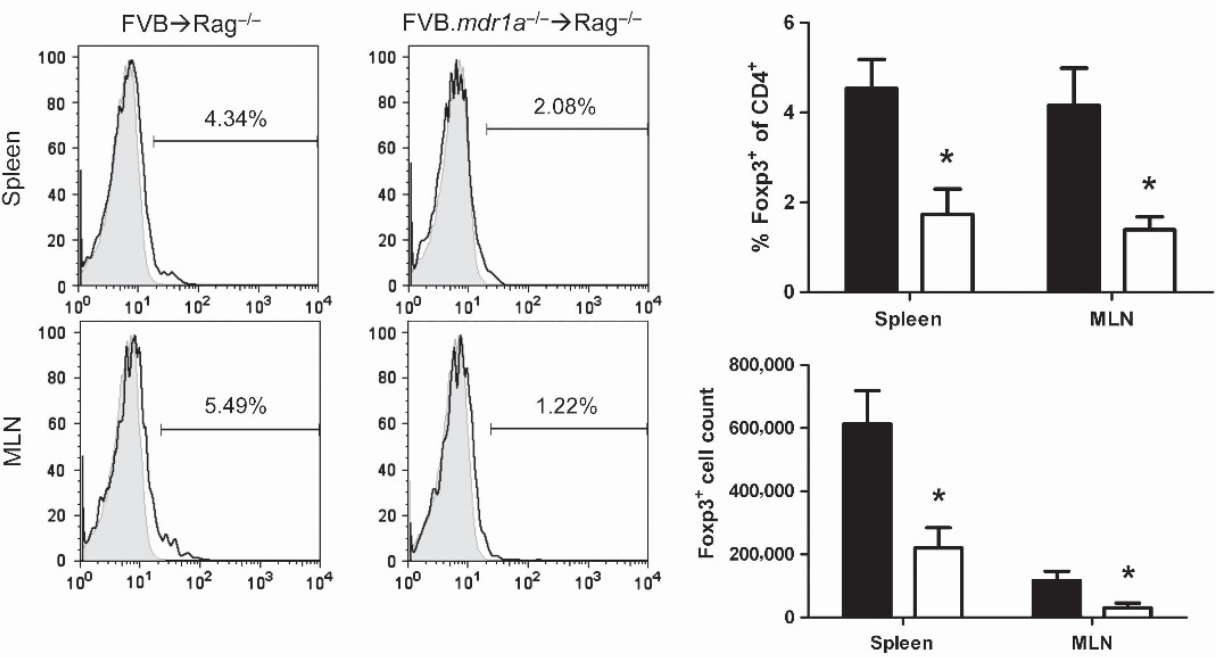

FVB $C D 4^{+} \mathrm{CD}^{-} 5^{-}$recipients

FVB. $m d r 1 a^{-1-} \mathrm{CD} 4^{+} \mathrm{CD} 25^{-}$recipients

Figure 7 FVB. $m d r 1 a^{-/-}$CD4 ${ }^{+}$CD25- cells show impaired Foxp3 ${ }^{+}$induced regulatory T cell (iTreg) generation in vivo. (a) A schematic of the adoptive transfer experiment. Splenocytes from FVB and FVB. mdr1a ${ }^{-/-}$mice were stained for CD4 and CD25, and subsequently isolated via fluorescence-activated cell sorting (FACS). Representative pre sort (left panels) and post sort (right panels) are shown for both FVB and FVB. $m d r 1 a^{-/-} .1 \times 10^{6} \mathrm{CD}^{+}{ }^{+} \mathrm{CD} 25^{-}$cells were then injected intraperitoneally (IP) into FVB. Rag2 ${ }^{-l-}$ recipients. After 14 days, the spleen, mesenteric lymph nodes (MLNs), and intestinal lamina propria were harvested from the recipients. (b) Foxp3 ${ }^{+}$expression on the gated CD4 ${ }^{+}$population of spleen and MLNs of FVB. Rag2 ${ }^{-/-}$recipients 14 days after adoptive transfer. ${ }^{*} P \leqslant 0.01$. Mean of six recipient mice per group $+\mathrm{s}$.d. is shown.

efficacy of Tregs in IBD patients. ${ }^{44}$ These data should warrant further investigation of the interactions between Tregs and TNF- $\alpha$ in IBD, particularly in patients on anti-TNF- $\alpha$ therapeutics.

P-gp has been shown to protect tumor and leukemia cell lines from caspase 3-mediated apoptosis, and a loss of P-gp could make a cell more susceptible to apoptosis. ${ }^{4,5}$ Interestingly, when this was tested in the FVB. $m d r 1 a^{-/-}$mice, there was no difference in activated caspase 3 expression on Foxp $3^{+}$Tregs, and no difference was observed in Fas/Fas ligand-mediated apoptosis, except in the MLNs. Although we cannot rule out that this slightly increased apoptosis of Foxp $3^{+}$cells in the MLNs contributes to the decreased numbers of Tregs in the small intestine, we do not believe the magnitude of this increase is enough to explain the dramatic loss of Tregs in the intestine. In addition, several recent studies have shown that activating caspase 3 may actually increase relative Treg numbers in various disease models, including colitis. ${ }^{45,46}$ Altered trafficking of Tregs could also explain why fewer Foxp $3^{+}$cells were present in the intestinal tissues of FVB. $m d r 1 a^{-1-}$ mice, but no difference was observed in $\alpha_{4} \beta_{7}$, CCR9, or CD103 expression in most cases. The increases in CCR6 in the intestine most likely indicate the presence of an increased number of cells that have encountered antigen. ${ }^{47}$ Although our experiments involving trafficking are not exhaustive, the data do suggest that common trafficking mechanisms are not responsible for the decreased Foxp $3^{+}$cells. In addition, these data indicate that blocking $\alpha_{4} \beta_{7}$ to inhibit Teff migration and intestinal inflammation may also prevent movement of Tregs into the intestine to control disease. ${ }^{48}$ This may especially true in patients with the MDR1 polymorphisms, as small intestinal CD ${ }^{+} \mathrm{Foxp}^{+} \mathrm{LP}$ cells have increased levels 
of $\alpha_{4} \beta_{7}$, indicating this is an important molecule for Treg trafficking to the gut.

Because increased apoptosis or altered Treg trafficking did not appear to be the cause of reduced intestinal Tregs, we further explored the possibility that there was altered Treg plasticity by testing for the presence of IFN- $\gamma$ - and IL-17-producing Foxp $3^{+}$cells from the spleen, MLNs, PPs, and intestinal LP. It has recently been shown that Foxp $3^{+}$cells are capable of secreting proinflammatory cytokines. ${ }^{37}$ In addition, it has been demonstrated in a model of type 1 diabetes that Foxp $3^{+}$cells can express retinoic acid-related orphan receptor $\gamma \mathrm{t}(\mathrm{ROR} \gamma \mathrm{t})$ and secrete IL-17, whereas in a model of colitis, Foxp $3^{+}$cells have been shown to switch to an IFN- $\gamma$ secreting Th1 phenotype in the presence of IL-12 in vitro. ${ }^{35,36}$ These recent studies describing Treg plasticity suggested that FVB. $m d r 1 a^{-1-}$ Tregs might be shifting to a Th1 or Th17 phenotype in an inflammatory setting. Surprisingly, no difference was observed in the Foxp $3^{+}$INF- $\gamma^{+}$or the Foxp $3^{+} \mathrm{IL}_{-} 17^{+}$populations when freshly isolated from FVB and FVB. $m d r 1 a^{-1-}$ animals. Although double-positive cells were detected, particularly in the small intestine, FVB and FVB. $m d r 1 a^{-1-}$ had similar percentages, thus suggesting that altered Treg plasticity probably is not the cause of lower Treg percentages in the FVB. $m d r 1 a^{-/-}$ intestine.

Although it does not appear that Foxp $3^{+}$cells are shifting to a proinflammatory phenotype, it is possible that the generation of Tregs, particularly iTregs, may be altered, especially in this intestinal environment, which is known to have increased intestinal permeability and increased proinflammatory cytokines in the intestine before inflammation. ${ }^{31,42}$ This inflammatory environment is known to include IL-6, which can shift T cells away from iTreg to a Th17 cell. ${ }^{38}$ To examine the generation of iTregs, purified $\mathrm{CD} 4{ }^{+} \mathrm{CD} 25^{-}$or $\mathrm{CD} 4{ }^{+} \mathrm{CD} 25^{+}$cells were treated with IL- 6 , TGF- $\beta$, or IL- 6 and TGF- $\beta$. TGF- $\beta$ is a cytokine known to induce Foxp3 expression and promote iTreg development, and hence the failure of TGF- $\beta$ to induce Foxp3 expression in FVB. $m d r 1 a^{-/-} \mathrm{CD} 4{ }^{+} \mathrm{CD} 25^{-}$cells was particularly surprising. ${ }^{15}$ To determine if this failure to induce iTregs was also true in vivo, we have demonstrated that FVB. $m d r 1 a^{-1-} \mathrm{CD} 4^{+} \mathrm{CD} 25^{-}$cells were less able to convert to Foxp $3^{+}$iTregs in an adoptive transfer model. Although it is possible that the presence of Foxp3 ${ }^{+}$ cells in the spleen and MLNs is a result of the small contaminating Foxp $3^{+}$population $(0.3 \%)$ proliferating and expanding, we do not believe this explains our results. We have observed that FVB. $m d r 1 a^{-1-} \mathrm{CD} 4{ }^{+} \mathrm{CD} 25^{+}$cells demonstrate higher levels of proliferation to in vitro stimulation than $\mathrm{FVB} \mathrm{CD} 4{ }^{+} \mathrm{CD} 25^{+}$cells, which would imply that if proliferation and expansion of this donor Foxp $3^{+}$population was responsible for the in vivo presence of $\mathrm{CD} 4^{+} \mathrm{Foxp}^{+}$cells in this transfer model, there should be more FVB. $m d r 1 a^{-1-}$ cells rather than less cells, as observed.

Taken together, these data would suggest that P-gp-deficient $\mathrm{T}$ cells are less able to be instructed to become iTregs. Although the mechanism for this inefficient Treg induction is unclear, one possibility can be found based on the knowledge that the normal balance between iTreg and Th17 induction in the presence of TGF- $\beta$ is tipped toward Th17 by the presence of IL- $6 .{ }^{49}$
It is known that one downstream effect of IL-6 is a dramatic decrease in P-gp expression. ${ }^{50,51}$ We propose that this downregulation is a required step for differentiation into a Th17 cell and blocks efficient differentiation into Tregs. This hypothesis is consistent with our results, as in our mice where P-gp expression is already absent, there is enhanced production of IL-17 and inhibited development of iTregs, even in the absence of IL-6. This hypothesis is also consistent with our observation that $\mathrm{CD} 4{ }^{+} \mathrm{CD} 25^{+}$Tregs have increased gene and functional expression of P-gp. We would propose that it is the small percentage of $\mathrm{CD} 4{ }^{+} \mathrm{CD} 25^{-}$cells that already express P-gp that are most susceptible to iTreg induction. Definitive experimental testing of this proposal awaits better cell surface markers for P-gp that can be used to sort out the P-gp expressing subsets that would be required. Because it has been shown that both iTregs and nTregs are vital in maintaining immune homeostasis in the intestines, this defect in iTreg generation could certainly be contributing to the inflammation in FVB. $m d r 1 a^{-1-}$ mice. ${ }^{25}$

This study has explored the role of Tregs in the FVB. $m d r 1 a^{-1-}$ mouse model of colitis, and determined that decreased levels of Tregs, specifically iTregs, is a result of altered T-cell lineage commitment. A deficiency in P-gp seems to prevent iTregs from being induced, particularly in mucosal compartments where iTregs are known to be a significant component of the total Treg population. ${ }^{52}$ This information has a direct impact on the human population, as polymorphisms in the human homolog of murine $m d r 1 a, M D R 1$, have been linked to IBD. ${ }^{12-14}$ The role of iTregs in MDR1 IBD patients has yet to be explored, and could provide vital information on the best way to treat patients with MDR1-specific polymorphisms. The generation of Tregs ex vivo for transfer back into patients has been explored for the treatment of autoimmune diseases, including IBD. Our data would suggest that it may be difficult to generate these cells from the patients themselves, depending on the mutation that a given patient may have. Tregs in IBD remain a mystery, as Tregs are decreased in peripheral blood, yet appear to have normal cell-contact function when isolated from the colon of patients with active disease. ${ }^{26}$ This suggests there may be alternative Treg functional defects in IBD patients, possibly similar to what we now describe in the FVB.mdrla $a^{-1-}$ model. In addition, this information may prove the importance of how patients with various mutations resulting in IBD are treated, and specific treatments based on the polymorphisms may provide more effective medical care in the future.

\section{METHODS}

Animals. FVB/N and FVB.129P2-Abcba1tm1BorN7 (FVB.mdr1a ${ }^{-1-}$ ) mice, as originally described by Schinkel et al. ${ }^{3}$ were purchased from Taconic Farms (Hudson, NY). FVB.Rag2 ${ }^{-1-}$ mice were a gift from Dr Benjamin E. Rich, Harvard Skin Diseases Research Center, Brigham and Women's Hospital Department of Dermatology. Unless otherwise noted, all animals used in this study were males, 6-8 weeks of age. Animals were bred and maintained under SPF conditions in Thoren Isolator racks (Hazleton, PA) under positive pressure. The Institutional Care and Use Committee of the University of Alabama at Birmingham approved all experiments. The specific pathogen-free conditions at the University of Alabama at Birmingham include absence of the following organisms, as determined by serological screening: mouse parvoviruses, 
including MPV-1, MPV-2, and minute virus of mice; mouse hepatitis virus, murine norovirus, Theiler's murine encephalomyelitis virus; mouse rotavirus (epizootic diarrhea of infant mice), Sendai virus; pneumonia virus of mice; reovirus; Mycoplasma pulmonis; lymphocytic choriomeningitis virus; mouse adenovirus; ectromelia (mousepox) virus; K polyoma virus; and mouse polyoma virus. Testing and other methods were as described at http://main.uab.edu/Sites/ComparativePathology/ surveillance/.

Cell isolation. Spleen, MLNs, and PPs were removed and cells isolated via single cell suspension by mechanical disruption. To isolate intestinal LP, small intestines and colons were removed, sliced open, and washed several times in Hanks' balanced salt solution supplemented with 2\% newborn calf serum (HyClone, Logan, UT), L-glutamine (Mediatech, Manassas, VA), penicillin/streptomycin (Mediatech), and 2-mercaptoethanol (Sigma-Aldrich, St Louis, MO). Intestines were then incubated with $0.2 \mathrm{mM}$ EDTA and $0.15 \mathrm{mg} \mathrm{m}^{-1}$ dithiothreitol (Fisher Scientific, Pittsburgh, PA) with gentle shaking at $37^{\circ} \mathrm{C}$ for $40 \mathrm{~min}$ (epithelial cells and intraepithelial lymphocytes were discarded), followed by incubation with $1 \mathrm{mg} \mathrm{ml}^{-1}$ collagenase type IV (Sigma-Aldrich) and $20 \mu \mathrm{g} \mathrm{ml}^{-1}$ DNase1 (Roche, Indianapolis, IN) with stirring at $37^{\circ} \mathrm{C}$ for $40 \mathrm{~min}$. Cells were then filtered through a $100 \mu \mathrm{m}$ stainless steel wire filter and collected at the interface of a $40 \% / 75 \%$ Percoll gradient. For some experiments, small intestine and colon (excluding cecum) were prepped and analyzed separately. All cells were rested for $18 \mathrm{~h}$ in RPMI supplemented with $10 \%$ fetal calf serum at $4^{\circ} \mathrm{C}$.

Flow cytometry. Cells were stained for both extracellular and intracellular molecules using the eBioscience Foxp3 Staining Buffer Set (eBioscience, San, Diego, CA). In summary, Fc receptors on target cells were blocked by incubating with anti-CD16/CD32 ( $1 \mu \mathrm{g}$ per sample) for $15 \mathrm{~min}$ at $4^{\circ} \mathrm{C}$. Cells were washed and stained with all extracellular antibodies for $30 \mathrm{~min}$ at $4^{\circ} \mathrm{C}$. Cells were washed and incubated with $100 \mu \mathrm{l}$ of eBioscience Permeabilization/Fixation Solution for $30 \mathrm{~min}$ at $4^{\circ} \mathrm{C}$. Cells were washed and stained with intracellular antibodies for $30 \mathrm{~min}$ at $4{ }^{\circ} \mathrm{C}$. Cells were then washed and resuspended in $1 \%$ paraformaldehyde solution in $0.15 \mathrm{M} \mathrm{NaCl}_{2}$ until analysis. If cells were being stained for cytokine production, cells were incubated at $37^{\circ} \mathrm{C}$ for $5 \mathrm{~h}$ in the presence of $50 \mathrm{ng} \mathrm{ml}^{-1}$ phorbol 12-myristate 13 -acetate, $750 \mathrm{ng} \mathrm{ml}^{-1}$ ionomycin, and GolgiStop (BD Biosciences, San Jose, CA). The antibodies used were: fluorescein isothiocyanate (FITC)-conjugated CD4 (clone L3T4, BD Biosciences), PerCP-Cy5.5-conjugated CD4 (clone RM4-5, BioLegend, San Diego, CA), phycoerythrin (PE)-conjugated CD25 (clonePC61, BD Biosciences), PE-conjugated CD103 (clone M290, BD Bioscience), PE-conjugated CCR9 (clone 242503, R\&D Systems, Minneapolis, MN), allophycocyanin (APC)-conjugated Foxp3 (clone FKJ-16s, eBioscience), PE-conjugated LPAM-1 ( $\alpha_{4} \beta_{7}$; clone DATK32, BD Biosciences), FITCconjugated INF- $\gamma$ (clone XMG1.2, BioLegend), and PE-conjugated IL-17A (clone TC11-18H10, BD Biosciences). All cells were analyzed via flow cytometry on a Becton Dickinson FACSCalibur (BD Biosciences) and events collected using CellQuest software. All analyses were done utilizing FlowJo software (Tree Star, Ashland, OR).

Cell separation. $\mathrm{CD} 4{ }^{+} \mathrm{CD} 25^{-}$and $\mathrm{CD} 4{ }^{+} \mathrm{CD} 25^{+}$cells were isolated by magnetic bead separation using the MACS CD $4{ }^{+} \mathrm{CD} 25^{+}$Cell Isolation Kit (Miltenyi Biotech, Auburn, CA) and following the manufacturer's protocol. Briefly, $\mathrm{CD} 4^{+}$cells were first isolated by negative selection. $\mathrm{CD} 25^{+}$cells were then selected for by positive selection, allowing separation of the $\mathrm{CD} 25^{-}$and $\mathrm{CD} 25^{+}$fractions. After isolation, CD $4+\mathrm{CD} 25+$ fraction contained $\sim 80 \% \mathrm{CD}^{+}{ }^{+}$Foxp $3^{+}$cells (Supplementary Figure S1 online).

RNA isolation and reverse transcriptase-PCR. RNA was obtained from fresh MACS isolated cells using the QIAgen RNeasy RNA extraction kit (QIAGEN, Valencia, CA). Complementary DNA (cDNA) was synthesized using the Transcriptor First Strand cDNA Synthesis Kit
(Roche, Pensburg, Germany). Quantitative real-time reverse transcriptase-PCR was performed using TaqMan Universal PCR Mix (Invitrogen, Grand Island, NY) in combination with Applied Biosystems TaqMan Gene Expression Assay primer probe sets (Applied Biosystems, Carlsbad, CA) for Abcb1a (Applied Biosystems Assay ID Mm00440761_ $\mathrm{m} 1)$. RNA expression level was calculated using the crossing threshold of detectable fluorescence level as determined by the RT cycler MX3000P (Stratagene, La Jolla, CA). Crossing thresholds were then averaged to get a gene-specific value that was then normalized to the average expression of the $18 \mathrm{~S}$ housekeeping gene for each strain and experimental condition studied. The $18 \mathrm{~S}$ housekeeping gene was utilized as the housekeeping gene in this study as published results indicate that it is expressed with relative stability under inflammatory conditions. ${ }^{53-55}$

R-123 flux assay. To measure P-gp, activity, the R-123 flux assay was modified from protocols previously described by Chaudhary et al. ${ }^{7,34}$ Freshly isolated cells were incubated with $100 \mathrm{ng} \mathrm{ml}^{-1} \mathrm{R}-123$ (Invitrogen) for $1 \mathrm{~h}$ at $4^{\circ} \mathrm{C}$. Cells were then washed and incubated with R-123 free media for $1-4 \mathrm{~h}$ at $4^{\circ} \mathrm{C}$ (Loaded control) or $37^{\circ} \mathrm{C}$ (Flux). Cells were then stained for appropriate surface molecules and analyzed immediately via flow cytometry.

Cell proliferation assay. FVB CD4 ${ }^{+} \mathrm{CD} 25^{-}$and $\mathrm{FVB}$ or FVB. $m d r 1 a^{-1-}$ $\mathrm{CD} 4{ }^{+} \mathrm{CD} 25^{+}$cells, freshly isolated via MACS as described above, were cultured alone at $2 \times 10^{6}$ cells per $\mathrm{ml}$, or co-cultured in $200 \mu \mathrm{l}$ RPMI supplemented with $10 \%$ fetal calf serum, penicillin/streptomycin (Mediatech), L-glutamine (Mediatech), and 2-mercaptoethanol (Sigma-Aldrich) in a 96-well plate coated with $1 \mu \mathrm{g} \mathrm{ml}^{-1}$ anti-CD3 (BD Biosciences) and $0.5 \mu \mathrm{g} \mathrm{ml}^{-1}$ anti-CD28 (BD Biosciences) for $96 \mathrm{~h}$ total. Supernatants for enzyme-linked immunosorbent assay and multiplex suspension cytokine array were collected after $72 \mathrm{~h}$ of culture and media replaced. Then, $1 \mu \mathrm{Ci}$ ${ }^{3} \mathrm{H}$-thymindine (Perkin-Elmer, Waltham, MA) was added for final $24 \mathrm{~h}$ of culture. The ${ }^{3} \mathrm{H}$-thymidine incorporation was quantitated by harvesting cells on a Perkin-Elmer Filtermate Unifilter-96 Harvester and analyzing on a Perkin-Elmer TopCount NXT scintillation counter using TopCount NXT software.

Apoptosis assays. To test for the presence of apoptotic (activated caspase $-3^{+}$) Foxp $3^{+}$cells in the intestine, immunohistochemical techniques were used as previously described. ${ }^{56}$ Briefly, tissue was isolated and placed in cassettes. Tissue was then immersion fixed in cold $4^{\circ} \mathrm{C}$ Bouin's solution (Fisher Scientific) overnight at $4^{\circ} \mathrm{C}$, then changed to ethanol, and embedded in paraffin. The tissue was cut into $5-\mu \mathrm{m}$ sections on a microtome and attached to precleaned microscope slides (Snowcoat X-tra; Surgipath, Richmond, IL). To visualize Foxp $3^{+}$and activated caspase $-3^{+}$cells within the tissue, slides were deparaffinized with CitriSolv (Fisher Scientific) followed by isopropanol, rinsed with DI water, and rehydrated with phosphate-buffered saline (PBS). Endogenous peroxidase was blocked by adding $3 \% \mathrm{H}_{2} \mathrm{O}_{2}$ to the slides for $10 \mathrm{~min}$ and washing the slides with DI water. Avidin- and biotin-blocking reagents (Avidin-Biotin Blocking Kit; Vector Laboratories, Burlingame, CA) were sequentially incubated on the slides for $15 \mathrm{~min}$ at room temperature in a humidity chamber. Slides were washed with PBS after each blocking solution. Slides were incubated at room temperature for 15 min with PBS supplemented with $1 \%$ bovine serum albumin, $0.2 \%$ powdered milk, and $0.3 \%$ Triton X-100 (Blocking Solution), and then the $10 \mu \mathrm{g} \mathrm{ml}^{-1}$ biotinylated Foxp3 (clone FKJ-16s, eBioscience) primary antibody diluted in PBS-BB to $10 \mu \mathrm{g} \mathrm{ml}^{-1}$ was added, and the slides were incubated overnight at $4^{\circ} \mathrm{C}$. After washing slides in PBS, $2.5 \mu \mathrm{g} \mathrm{ml}^{-1}$ streptavidin-horseradish peroxidase (Jackson ImmunoResearch, West Grove, PA; diluted in Blocking Solution) was incubated on the slide for $30 \mathrm{~min}$ at room temperature. Slides were then incubated with FITC Tyramide Amplification Reagent (Perkin-Elmer) for $30 \mathrm{~min}$ at room temperature in the dark according to the manufacture's protocol. Remaining peroxidase was then blocked by repeating the incubation with $\mathrm{H}_{2} \mathrm{O}_{2}$ for $10 \mathrm{~min}$, and then the activated caspase 3 (clone D175, Cell Signaling Technologies, Danvers, MA) primary 
antibody (diluted 1:250 in Blocking Solution) was added, and the slides were incubated overnight at $4^{\circ} \mathrm{C}$. After washing slides in PBS, $2.5 \mu \mathrm{g} \mathrm{ml}^{-1}$ donkey anti-rabbit-horseradish peroxidase (Jackson ImmunoResearch) was diluted in Blocking Solution and incubated on the slide for $30 \mathrm{~min}$ at room temperature. Slides were then incubated with Cy3 Tyramide Amplification Reagent (Perkin-Elmer) for $30 \mathrm{~min}$ at room temperature in the dark according to the manufacturer's protocol. This dual tyramide signal amplification (TSA) staining protocol is performed as previously described. ${ }^{57}$ After a PBS rinse, slides were counterstained with Hoechst (33342, Sigma, St Louis, MO) to label nuclei. Tissue was visualized using a Ziess AxioScope and images were captured and analyzed using a Ziess AxioCam with AxioVision 4.7 software (Carl Ziess, Peabody, MA).

To investigate sensitivity to apoptosis induction, cells were isolated from the spleen, MLNs, PPs, and LP as described above. $1 \times 10^{6}$ cells were then incubated in a round-bottom 96 -well plate for $18 \mathrm{~h}$ in the presence of $10 \mu \mathrm{g} \mathrm{ml}^{-1}$ anti-CD95 (clone Jo2, BD Biosciences). Cells were then stained for flow cytometry as described above.

Cytokine measurements. Enzyme-linked immunosorbent assays were performed to measure levels of IL-10, IL-17A, and IFN$\gamma$. Briefly, Immulon 96-well plates (Thermo-Fisher Scientific, Waltham, MA) were coated with capture antibody $\left(4.0 \mu \mathrm{g} \mathrm{ml}^{-1}\right.$ IL-10: clone JES5-2A5, $1 \mu \mathrm{g} \mathrm{ml}^{-1}$ IL-17A: clone TC11-18H10.1, and $0.5 \mu \mathrm{g} \mathrm{ml}^{-1}$ IFN- $\gamma$ : clone R4-6A2) overnight at $4^{\circ} \mathrm{C}$. Plates were then washed and blocked with PBS containing $10 \%$ newborn calf serum. Plates were again washed and culture supernatant or known standard was added for $2 \mathrm{~h}$ at room temperature. Standard consisted of seven dilutions and a blank, run in triplicate. Dilutions started at $5 \mu \mathrm{g} \mathrm{ml}^{-1} \mathrm{IL}-10$, $2.5 \mu \mathrm{g} \mathrm{ml}^{-1} \mathrm{IL}-17$, and $5 \mu \mathrm{g} \mathrm{ml}^{-1}$ INF- $\gamma$, and were diluted 1:2. Samples were washed off and the biotinylated detection antibody $\left(0.75 \mu \mathrm{g} \mathrm{ml}^{-1}\right.$ IL-10: clone JES5-16E3, $0.5 \mu \mathrm{g} \mathrm{ml}^{-1}$ IL-17A: clone TC11-8H4, and $1 \mu \mathrm{g} \mathrm{ml}^{-1}$ IFN- $\gamma$ : clone XMG1.2) was added for $1 \mathrm{~h}$ at room temperature. Plates were washed again, and streptavidin-horseradish peroxidase (Jackson ImmunoResearch) was added for $30 \mathrm{~min}$. Plates were washed for a final time, and 3,3',5,5' -tetramethylbenzidine (Thermo Scientific, Rockford, IL) was added and developed for $15 \mathrm{~min}$ (IL-17A and IFN- $\gamma$ ) or $30 \mathrm{~min}$ (IL-10). The reaction was stopped by adding $\mathrm{H}_{2} \mathrm{SO}_{4}$ and the plates were read on a VERSAmax microplate reader (Molecular Devices, Sunnyvale, CA) at $450 \mathrm{~nm}$. All capture and detection antibodies were purchased from BioLegend.

Multiplex analysis of cell culture supernatants was done to measure levels of IFN- $\gamma$, IL-2, IL-10, IL-17A, and TNF- $\alpha$ using a Luminex-based Bio-Plex multiplex suspension protein assay (Bio-Rad, Hercules, CA) Bio-Plex Assay kit following the manufacture's protocol.

Chemotaxis assay. The T-cell chemokine receptor activation and chemotaxis assay was performed as previously described. ${ }^{58}$ Because cell activation increases $\mathrm{CD} 4^{+}$cell chemotaxis, cells were isolated and stimulated before the chemotaxis analysis. $\mathrm{CD} 4^{+}$lymphocytes were isolated from spleens using the BD CD ${ }^{+}$T Lymphocyte Enrichment Kit (BD Biosciences) following the manufacturer's protocol. Cells were then plated at $5 \times 10^{5}$ cells per well in $200 \mu \mathrm{l}$ RPMI supplemented with $10 \%$ fetal calf serum, penicillin/streptomycin (Mediatech), L-glutamine (Mediatech), 2-mercaptoethanol (Sigma-Aldrich), and $10 \mathrm{ng} \mathrm{ml}^{-1}$ recombinant mouse IL-2 (BioLegend) in a 96-well plate coated with $1 \mu \mathrm{g} \mathrm{ml}^{-1}$ anti-CD3 (BD Biosciences) and $0.5 \mu \mathrm{g} \mathrm{ml}^{-1}$ anti-CD28 (BD Biosciences) and cultured for $48 \mathrm{~h}$ at $37^{\circ} \mathrm{C}$. Cells were then rested in a plate with no CD3/CD28 stimulation with fresh media and IL- 2 for $48 \mathrm{~h}$ at $37^{\circ} \mathrm{C}$. After resting, the cells were washed, counted, and the $\mathrm{CD} 4{ }^{+} \mathrm{CD} 25^{+}$population was isolated using the MACS CD $4{ }^{+} \mathrm{CD} 25^{+}$Cell Isolation Kit (Miltenyi Biotech), following the manufacturer's protocol.

Once isolated, the cells were rested for $1 \mathrm{~h}$ at $37^{\circ} \mathrm{C}$ to recover from isolation. Then, each well of the upper chamber of the $3.0 \mu \mathrm{m}$ transwell (Millipore, Billerica, MA) was coated with $50 \mu \mathrm{l}$ of $10 \mu \mathrm{g} \mathrm{ml}^{-1}$ bovine plasma fibronectin (Sigma-Aldrich) for $1 \mathrm{~h}$ at $37^{\circ} \mathrm{C}$. Fibronectin was then removed, and upper chambers air dried for $30 \mathrm{~min}$ at room temperature. Next, $150 \mu \mathrm{l}$ of chemokine mixture (various concentrations of chemokines used, from 1 to $100 \mathrm{ng} \mathrm{ml}^{-1}$ ) in RPMI supplemented with $0.5 \%$ fetal bovine serum was placed in the bottom chamber. $5 \times 10^{5}$ cells in $50 \mu \mathrm{l}$ of RPMI supplemented with $0.5 \%$ fetal bovine serum were placed in the upper chambers. Plates were incubated for $3 \mathrm{~h}$ at $37^{\circ} \mathrm{C}$. Upper chambers were removed, and migrated cells in the bottom wells were counted by hemocytometer to determine the number of cells migrated.

Cell culture. To investigate Treg plasticity and iTreg induction, splenic $\mathrm{CD} 4{ }^{+} \mathrm{CD} 25^{-}$and $\mathrm{CD} 4{ }^{+} \mathrm{CD} 25^{+}$cells were isolated and separated as described above. $3 \times 10^{5}$ freshly separated cells were then added to a 96-well flat-bottom plate coated with anti-CD3 $\left(1 \mu \mathrm{g} \mathrm{ml}^{-1}\right)$ and anti$\mathrm{CD} 28\left(0.5 \mu \mathrm{g} \mathrm{ml}^{-1}\right)$ for $72 \mathrm{~h}$ at $37^{\circ} \mathrm{C}$ in media alone, or in the presence of $5 \mathrm{ng} \mathrm{ml}^{-1}$ recombinant human TGF- $\beta, 25 \mathrm{ng} \mathrm{ml}^{-1}$ recombinant mouse IL-6, or $10 \mathrm{ng} \mathrm{ml}^{-1}$ recombinant mouse IL-1 $\beta$ (or combinations of those cytokines). After $72 \mathrm{~h}$, cells were rested in fresh media for $24 \mathrm{~h}$, and then stained as described above. All cytokines were purchased from BioLegend.

Adoptive transfer. To test the in vivo capability of FVB.mdr1a $a^{-1-}$ $\mathrm{CD} 4{ }^{+} \mathrm{CD} 25^{-}$cells to become iTregs, adoptive transfer experiments were performed as previously described. ${ }^{59}$ Cells for adoptive transfer were obtained from 6-8-week-old FVB and FVB. $m d r 1 a^{-/-}$spleens as described above. Once in single-cell suspension, the cells were stained for CD4 and CD25 as described above. CD $4^{+} \mathrm{CD} 25^{-}$cells were then sorted using a BD Biosciences FACSAria cell sorter (BD Biosciences), obtaining $98-99 \%$ purity of the $\mathrm{CD} 4{ }^{+} \mathrm{CD} 25^{-}$population. After sorting, cells were washed and resuspended in PBS, and $1 \times 10^{6} \mathrm{CD} 4^{+} \mathrm{CD} 25^{-}$cells were delivered in a volume of $100 \mu \mathrm{l}$ PBS by intraperitoneal injection into 6-8-week-old FVB.Rag2 ${ }^{-/-}$recipients. After 14 days, the recipient mice were killed, and the spleen, MLNs, and intestinal LP were isolated as described above. The cells were then stained for CD4, CD25, and Foxp3 and analyzed as described above.

Statistical analysis. Statistics on continuous data were performed using the unpaired $t$-test in GraphPad Prism software (San Diego, CA). The $P$-values of $\leqslant 0.05$ are shown.

SUPPLEMENTARY MATERIAL is linked to the online version of the paper at http://www.nature.com/mi

\section{ACKNOWLEDGMENTS}

We thank A. Metz and C. Steele for assistance with multiplex analysis and E. Keyser with the UAB Rheumatic Diseases Analytic and Preparative Cytometry Facility (NIH 5P30 AR048311) for FACS sorting assistance. We also thank J. McNaught for slide preparation and M. Harris for animal husbandry, and members of the Lorenz lab for valuable advice. This study was supported in part by NIH grants R01 DK059911; P01 DK071176; and University of Alabama at Birmingham Digestive Diseases Research Development Center grant P30 DK064400. S.M.T. is supported by the Howard Hughes Medical Institute Med into Grad Fellowship and the University of Alabama at Birmingham Carmichael Fund. Aspects of this project were conducted in biomedical research space that was constructed with funds supported in part by NIH grant C06RR020136.

\section{DISCLOSURE}

The authors declared no conflict of interest.

\section{(C) 2013 Society for Mucosal Immunology}

\section{REFERENCES}

1. Panwala, C.M., Jones, J.C. \& Viney, J.L. A novel model of inflammatory bowel disease: mice deficient for the multiple drug resistance gene, mdr1a, spontaneously develop colitis. J. Immunol. 161, 5733-5744 (1998).

2. Maggio-Price, L. et al. Dual infection with helicobacter bilis and helicobacter hepaticus in p-glycoprotein-deficient mdr1a-/ - mice results in colitis that progresses to dysplasia. Am. J. Pathol. 166, 1793-1806 (2005) 
3. Schinkel, A.H. et al. Disruption of the mouse mdr1a P-glycoprotein gene leads to a deficiency in the blood-brain barrier and to increased sensitivity to drugs. Cell 77, 491-502 (1994).

4. Smyth, M.J., Krasovskis, E., Sutton, V.R. \& Johnstone, R.W. The drug efflux protein, P-glycoprotein, additionally protects drug-resistant tumor cells from multiple forms of caspase-dependent apoptosis. Proc. Natl. Acad. Sci. USA 95, 7024-7029 (1998).

5. Johnstone, R.W., Cretney, E. \& Smyth, M.J. P-glycoprotein protects leukemia cells against caspase-dependent, but not caspaseindependent, cell death. Blood 93, 1075-1085 (1999).

6. Drach, D. et al. Subpopulations of normal peripheral blood and bone marrow cells express a functional multidrug resistant phenotype. Blood 80, 2729-2734 (1992).

7. Chaudhary, P.M., Mechetner, E.B. \& Roninson, I.B. Expression and activity of the multidrug resistance P-glycoprotein in human peripheral blood lymphocytes. Blood 80, 2735-2739 (1992).

8. Coon, J.S. et al. Multidrug resistance activity in human lymphocytes. Hum. Immunol. 32, 134-140 (1991).

9. Randolph, G.J. et al. A physiologic function for p-glycoprotein (MDR-1) during the migration of dendritic cells from skin via afferent lymphatic vessels. Proc. Natl. Acad. Sci. USA 95, 6924-6929 (1998).

10. van de Ven, R., Scheffer, G.L., Scheper, R.J. \& de Gruijl, T.D. The ABC of dendritic cell development and function. Trends Immunol. 30, 421-429 (2009).

11. Staley, E.M., Dimmitt, R.A., Schoeb, T.R., Tanner, S.M. \& Lorenz, R.G. Critical role for P-glycoprotein expression in hematopoietic cells in the Fvb.Mdr1a-/ - model of colitis. J. Pediatr. Gastroenterol. Nutr. 53, 666-673 (2011).

12. Annese, V. et al. Multidrug resistance 1 gene in inflammatory bowel disease: a meta-analysis. World J. Gastroenterol. 12, 3636-3644 (2006).

13. Onnie, C.M. et al. Associations of allelic variants of the multidrug resistance gene (ABCB1 or MDR1) and inflammatory bowel disease and their effects on disease behavior: a case-control and meta-analysis study. Inflamm. Bowel Dis. 12, 263-271 (2006).

14. Ho, G.T. et al. ABCB1/MDR1 gene determines susceptibility and phenotype in ulcerative colitis: discrimination of critical variants using a gene-wide haplotype tagging approach. Hum. Mol. Genet. 15, 797-805 (2006).

15. Chen, W. et al. Conversion of peripheral CD4+CD25 - naive T cells to $\mathrm{CD} 4+\mathrm{CD} 25+$ regulatory T cells by TGF-beta induction of transcription factor Foxp3. J. Exp. Med. 198, 1875-1886 (2003).

16. Razmara, M., Hilliard, B., Ziarani, A.K., Chen, Y.H. \& Tykocinski, M.L. CTLA- 4 x Ig converts naive CD4+CD25 - T cells into CD4+CD25+ regulatory T cells. Int. Immunol. 20, 471-483 (2008).

17. Sakaguchi, S., Wing, K., Onishi, Y., Prieto-Martin, P. \& Yamaguchi, T. Regulatory $T$ cells: how do they suppress immune responses? Int. Immunol. 21, 1105-1111 (2009).

18. Hori, S., Nomura, T. \& Sakaguchi, S. Control of regulatory T cell development by the transcription factor Foxp3. Science 299, 1057-1061 (2003)

19. Fontenot, J.D., Gavin, M.A. \& Rudensky, A.Y. Foxp3 programs the development and function of CD4+CD25+ regulatory T cells. Nat. Immunol. 4, 330-336 (2003).

20. Fantini, M.C. et al. Cutting edge: TGF-beta induces a regulatory phenotype in CD4+CD25 - T cells through Foxp3 induction and down-regulation of Smad7. J. Immunol. 172, 5149-5153 (2004).

21. Rao, P.E., Petrone, A.L. \& Ponath, P.D. Differentiation and expansion of $T$ cells with regulatory function from human peripheral lymphocytes by stimulation in the presence of TGF-\{beta\}. J. Immunol. 174, 1446-1455 (2005).

22. Coombes, J.L. et al. A functionally specialized population of mucosal CD103+ DCs induces Foxp3+ regulatory T cells via a TGF-beta and retinoic acid-dependent mechanism. J. Exp. Med. 204, 1757-1764 (2007).

23. Sun, C.M. et al. Small intestine lamina propria dendritic cells promote de novo generation of Foxp3T reg cells via retinoic acid. J. Exp. Med. 204, 1775-1785 (2007).

24. Cong, Y., Weaver, C.T., Lazenby, A. \& Elson, C.O. Bacterial-reactive T regulatory cells inhibit pathogenic immune responses to the enteric flora. J. Immunol. 169, 6112-6119 (2002).

25. Haribhai, D. et al. A central role for induced regulatory $T$ cells in tolerance induction in experimental colitis. J. Immunol. 182, 3461-3468 (2009).
26. Holmén, N. et al. Functional CD4+CD25high regulatory T cells are enriched in the colonic mucosa of patients with active ulcerative colitis and increase with disease activity. Inflamm. Bowel Dis. 12, 447-456 (2006).

27. Makita, S. et al. CD4+CD25bright T cells in human intestinal lamina propria as regulatory cells. J. Immunol. 173, 3119-3130 (2004).

28. Saruta, M. et al. Characterization of FOXP3 $+\mathrm{CD} 4+$ regulatory T cells in Crohn's disease. Clin. Immunol. 125, 281-290 (2007).

29. Fedorak, R.N. et al. Recombinant human interleukin 10 in the treatment of patients with mild to moderately active Crohn's disease. The Interleukin 10 Inflammatory Bowel Disease Cooperative Study Group. Gastroenterology $119,1473-1482$ (2000).

30. Schreiber, S. et al. Safety and efficacy of recombinant human interleukin 10 in chronic active Crohn's disease. Crohn's Disease IL-10 Cooperative Study Group. Gastroenterology 119, 1461-1472 (2000).

31. Staley, E.M., Schoeb, T.R. \& Lorenz, R.G. Differential susceptibility of P-glycoprotein deficient mice to colitis induction by environmental insults. Inflamm. Bowel Dis. 15, 684-696 (2009).

32. Fujiwara, D., Chen, L., Wei, B. \& Braun, J. Small intestine CD11C+ CD8+ T cells suppress CD4+ T cell-induced immune colitis. Am. J. Physiol. Gastrointest. Liver Physiol. 300, G939-G947 (2011).

33. McFarland, A.P. et al. Localized delivery of interferon- $\beta$ by Lactobacillus exacerbates experimental colitis. PLoS One 6, e16967 (2011).

34. Chaudhary, P.M. \& Roninson, I.B. Expression and activity of P-glycoprotein, a multidrug efflux pump, in human hematopoietic stem cells. Cell 66, 85-94 (1991).

35. Tartar, D.M. et al. FoxP3+RORgammat+ Thelper intermediates display suppressive function against autoimmune diabetes. J. Immunol. 184, 3377-3385 (2010).

36. Feng, T., Cao, A.T., Weaver, C.T., Elson, C.O. \& Cong, Y. Interleukin-12 converts Foxp3+ regulatory T cells to interferon- $\gamma$-producing Foxp3+ T cells that inhibit colitis. Gastroenterology 140, 2031-2043 (2011).

37. Zhou, X. et al. Instability of the transcription factor Foxp3 leads to the generation of pathogenic memory T cells in vivo. Nat. Immunol. 10, 1000-1007 (2009).

38. Lee, Y.K., Mukasa, R., Hatton, R.D. \& Weaver, C.T. Developmental plasticity of Th17 and Treg cells. Curr. Opin. Immunol. 21, 274-280 (2009).

39. Thornton, A.M. et al. Expression of Helios, an Ikaros transcription factor family member, differentiates thymic-derived from peripherally induced Foxp3+ T regulatory cells. J. Immunol. 184, 3433-3441 (2010).

40. Gottschalk, R.A., Corse, E. \& Allison, J.P. Expression of helios in peripherally induced Foxp3+ regulatory T cells. J. Immunol. 188, 976-980 (2012).

41. Collett, A. et al. Early molecular and functional changes in colonic epithelium that precede increased gut permeability during colitis development in mdr1a(-/-) mice. Inflamm. Bowel Dis. 14, 620-631 (2008).

42. Resta-Lenert, S., Smitham, J. \& Barrett, K.E. Epithelial dysfunction associated with the development of colitis in conventionally housed mdr1a-/ - mice. Am. J. Physiol. Gastrointest. Liver Physiol. 289, G153-G162 (2005).

43. Esplugues, E. et al. Control of TH17 cells occurs in the small intestine. Nature 475, 514-518 (2011).

44. Boschetti, G. et al. Therapy with anti-TNF $\alpha$ antibody enhances number and function of Foxp3(+) regulatory T cells in inflammatory bowel diseases. Inflamm. Bowel Dis. 17, 160-170 (2011).

45. Yarkoni, S., Sagiv, Y., Kaminitz, A., Farkas, D.L. \& Askenasy, N. Targeted therapy to the IL-2R using diphtheria toxin and caspase-3 fusion proteins modulates Treg and ameliorates inflammatory colitis. Eur. J. Immunol. 39, 2850-2864 (2009).

46. Penaranda, C., Tang, Q. \& Bluestone, J.A. Anti-CD3 therapy promotes tolerance by selectively depleting pathogenic cells while preserving regulatory T cells. J. Immunol. 187, 2015-2022 (2011).

47. Kleinewietfeld, M. et al. CCR6 expression defines regulatory effector/ memory-like cells within the CD25(+)CD4+ T-cell subset. Blood 105, 2877-2886 (2005).

48. Ghosh, S. \& Panaccione, R. Anti-adhesion molecule therapy for inflammatory bowel disease. Therap. Adv. Gastroenterol. 3, 239-258 (2010). 
49. Korn, T. et al. IL-6 controls Th17 immunity in vivo by inhibiting the conversion of conventional T cells into Foxp3+ regulatory T cells. Proc. Natl. Acad. Sci. USA 105, 18460-18465 (2008).

50. Sukhai, M., Yong, A., Kalitsky, J. \& Piquette-Miller, M. Inflammation and interleukin-6 mediate reductions in the hepatic expression and transcription of the mdr1a and mdr1b genes. Mol. Cell. Biol. Res. Commun. 4, 248-256 (2000).

51. Sukhai, M., Yong, A., Pak, A. \& Piquette-Miller, M. Decreased expression of P-glycoprotein in interleukin-1 beta and interleukin-6 treated rat hepatocytes. Inflamm. Res. 50, 362-370 (2001).

52. Murai, M., Krause, P., Cheroutre, H. \& Kronenberg, M. Regulatory T-cell stability and plasticity in mucosal and systemic immune systems. Mucosal. Immunol. 3, 443-449 (2010).

53. Bas, A., Forsberg, G., Hammarström, S. \& Hammarström, M.L. Utility of the housekeeping genes 18S rRNA, beta-actin and glyceraldehyde-3phosphate-dehydrogenase for normalization in real-time quantitative reverse transcriptase-polymerase chain reaction analysis of gene expression in human T lymphocytes. Scand. J. Immunol. 59, 566-573 (2004).
54. Ropenga, A., Chapel, A., Vandamme, M. \& Griffiths, N.M. Use of reference gene expression in rat distal colon after radiation exposure: a caveat. Radiat. Res. 161, 597-602 (2004).

55. Rubie, C. et al. Housekeeping gene variability in normal and cancerous colorectal, pancreatic, esophageal, gastric and hepatic tissues. Mol. Cell. Probes 19, 101-109 (2005).

56. Schmitz, J.M., Durham, C.G., Ho, S.B. \& Lorenz, R.G. Gastric mucus alterations associated with murine helicobacter infection. J. Histochem. Cytochem. 57, 457-467 (2009).

57. Zaidi, A.U., Enomoto, H., Milbrandt, J. \& Roth, K.A. Dual fluorescent in situ hybridization and immunohistochemical detection with tyramide signal amplification. J. Histochem. Cytochem. 48, 1369-1375 (2000)

58. Siveke, J.T. \& Hamann, A. Thelper 1 and T helper 2 cells respond differentially to chemokines. J. Immunol. 160, 550-554 (1998).

59. Shaw, M.H., Kamada, N., Kim, Y.G. \& Núñez, G. Microbiota-induced $\mathrm{IL}-1 \beta$, but not IL-6, is critical for the development of steady-state $\mathrm{TH} 17$ cells in the intestine. J. Exp. Med. 209, 251-258 (2012). 